\title{
Peptidoglycan Muropeptides: Release, Perception, and Functions as Signaling Molecules
}

\section{OPEN ACCESS}

Edited by:

Patrick Joseph Moynihan, University of Birmingham,

United Kingdom

Reviewed by: Joseph P. Dillard, University of Wisconsin-Madison, United States

Jonathan Dworkin,

Columbia University,

United States

*Correspondence:

Felipe Cava

felipe.cava@molbiol.umu.se

Specialty section:

This article was submitted to Microbial Physiology and Metabolism, a section of the journal

Frontiers in Microbiology

Received: 09 October 2018

Accepted: 27 February 2019

Published: 28 March 2019

Citation:

Irazoki O, Hernandez SB and Cava F (2019) Peptidoglycan Muropeptides:

Release, Perception, and Functions as Signaling Molecules.

Front. Microbiol. 10:500.

doi: 10.3389/fmicb.2019.00500

\section{Oihane Irazoki, Sara B. Hernandez and Felipe Cava*}

Laboratory for Molecular Infection Medicine Sweden, Department of Molecular Biology, Umeå Centre for Microbial Research Umeå University, Umeå, Sweden

Peptidoglycan (PG) is an essential molecule for the survival of bacteria, and thus, its biosynthesis and remodeling have always been in the spotlight when it comes to the development of antibiotics. The peptidoglycan polymer provides a protective function in bacteria, but at the same time is continuously subjected to editing activities that in some cases lead to the release of peptidoglycan fragments (i.e., muropeptides) to the environment. Several soluble muropeptides have been reported to work as signaling molecules. In this review, we summarize the mechanisms involved in muropeptide release (PG breakdown and PG recycling) and describe the known PG-receptor proteins responsible for $P G$ sensing. Furthermore, we overview the role of muropeptides as signaling molecules, focusing on the microbial responses and their functions in the host beyond their immunostimulatory activity.

Keywords: peptidoglycan, PG cleaving enzymes, PG recycling, PG receptors, signaling functions, bacterial interactions

\section{INTRODUCTION}

Most bacteria surround themselves with a protective cell wall to repel environmental challenges. These tough cell walls are primarily composed of a peptidoglycan (PG) exoskeleton, also called the murein sacculus (Vollmer et al., 2008a; de Pedro and Cava, 2015). PG is a highly dynamic macromolecule subjected to constant remodeling in response to changing environmental conditions (Horcajo et al., 2012). It counteracts osmotic pressure, maintains cell shape and integrity, and serves as a protective barrier against physical, chemical, and biological threats (Holtje, 1998; Vollmer et al., 2008a). PG is found on the outside of the cytoplasmic membrane of almost all bacteria (Nanninga, 1998; Mengin-Lecreulx and Lemaitre, 2005) and presents a conserved overall composition and biogenesis, although the complexity and thickness of the structure vary (Cava and de Pedro, 2014). Peptidoglycan also serves as a scaffold for anchoring other cell envelope components such as proteins (Dramsi et al., 2008) and teichoic acids (Neuhaus and Baddiley, 2003).

Structurally speaking, the PG sacculus is made up of linear glycan strands cross-linked to each other by short peptide chains forming a continuous layer. The glycan backbone generally consists of repeating disaccharides of $\mathrm{N}$-acetylglucosamine (NAG) and $\mathrm{N}$-acetylmuramic acid (NAM) covalently attached to a peptide chain containing 2-5 amino acid residues. The archetypical peptide stem structure is L-alanine, D-glutamic acid, a dibasic amino acid [typically 

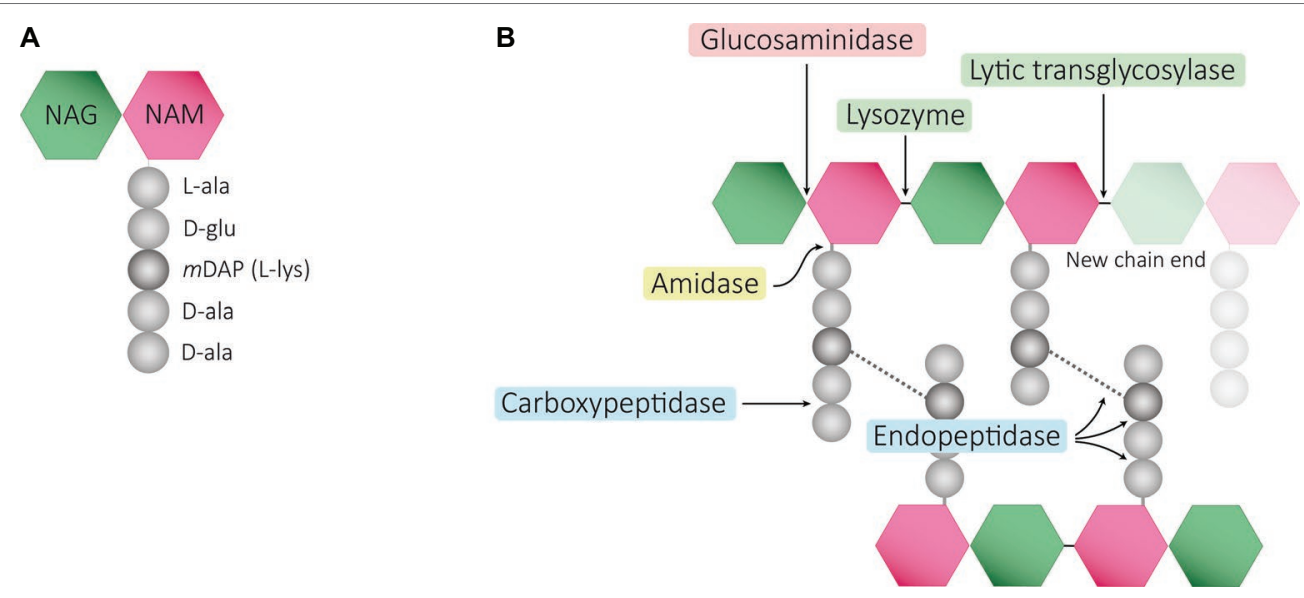

FIGURE 1 | Schematic representation of muropeptides and peptidoglycan. (A) The archetypical structure of muropeptides consist of NAG-NAM disaccharides

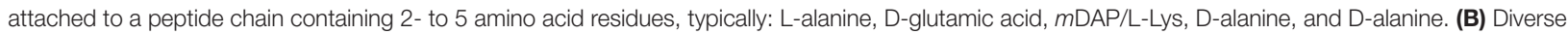
cleavage points of PG cleaving enzymes: glucosaminidases (pink), amidases (yellow), peptidases (blue), and muramidases (green) are shown.

meso-diaminopimelic acid (mDAP) or L-lysine], D-alanine, and D-alanine (Figure 1A). Some of the peptide chains from adjacent glycan strands are cross-linked, resulting in a thick threedimensional multi-layered meshwork. This arrangement is widely conserved across most bacterial species; however, the chemistry of the residues of the peptide stem, the glycan chains, and the type of crosslinking can vary (Vollmer et al., 2008a). These variations alter the properties of the cell wall and allow for great diversity in fine structure and architecture (Schleifer and Kandler, 1972; Vollmer and Bertsche, 2008; Cava and de Pedro, 2014; Turner et al., 2014). For more detailed information about PG structure, synthesis, and regulation, we refer to extended reviews (Vollmer et al., 2008a; Typas et al., 2011; Egan et al., 2017).

During growth and maturation, PG is degraded by dedicated enzymes, which shed PG fragments (or muropeptides) in a process termed PG turnover. In E. coli, in a single generation of growth, as much as $50 \%$ of the PG is excised from the cell wall as anhydromuropeptides, suggesting a robust turnover of the cell wall (Doyle et al., 1988). Around the 95\% of these are efficiently recovered and reused through the PG-recycling pathway (Goodell and Schwarz, 1985; Park and Uehara, 2008).

In recent years, PG has been of much interest not only because it is one of the major antibiotic targets (Kohanski et al., 2010) but also due to its importance in host physiology and metabolism since it presents immunostimulatory activities (Girardin et al., 2003a,b). Some PG-derived fragments are recycled for cell wall biosynthesis but they are also used in bacterial communication and are detected by eukaryotes to initiate an immune response (Girardin et al., 2003a,b; Boudreau et al., 2012; Woodhams et al., 2013; Dworkin, 2014). Recent data suggest that muropeptides have many diverse roles, including involvement in symbiotic associations, microbial interactions, and pathogenesis in animals and plants. In this review, we focus on the signaling functions of PG fragments, describing the mechanisms involved in the release of these molecules and the means by which they are sensed by bacterial and host cells.

\section{MUROPEPTIDES RELEASE}

It is well documented that the PG sacculus is remodeled during bacterial growth and that this process causes the release of muropeptides. The discharge of PG fragments can occur as a consequence of the disruption of PG during growth or by the complete lysis of cells.

\section{PG Cleaving Enzymes}

Cleavage of PG is required for fundamental physiological processes in bacteria such as enlargement of the PG sacculus during bacterial growth and cell separation during cell division (Holtje, 1998; Layec et al., 2008; Uehara et al., 2010; Typas et al., 2011; Uehara and Bernhardt, 2011; Waldemar, 2012); incorporation and assembly of protein complexes into the cell wall (e.g., secretion, conjugation, and flagellum systems) (Dijkstra and Keck, 1996; Koraimann, 2003; Scheurwater et al., 2008; Scheurwater and Burrows, 2011; Stohl et al., 2013); or sporulation and resuscitation of dormant states (Keep et al., 2006; Wyckoff et al., 2012; Popham and Bernhards, 2015). Enzymes cleaving the bonds that exist within PG are generally known as PG hydrolases (PGHs), and although some (i.e., lytic transglycosylases) do not present chemical hydrolytic activity, from now on we will refer to all them as PGHs. Despite the large number and diversity of proteins cleaving the PG, they can be grouped accordingly to the type of the bond cleaved such as glycosidases (cleaving glycosidic bonds of the glycan strands), amidases (hydrolyzing the amide bond between the first amino acid of the stem peptide and the NAM), and peptidases (cleaving bonds between amino acids present in the stem peptides) (Figure 1B). They often act on a particular type of PG, cleaving intact high-molecular-weight murein sacculi and its soluble fragments (Vollmer et al., 2008b).

PG glycan chains contain two glycosidic bonds sensitive to the activity of glycosidases: the bond between a NAG and the 
adjacent NAM is hydrolyzed by $N$-Acetyl- $\beta$-glucosaminidases ( $N$-acetylglucosaminidases), while muramidases (or muralytic enzymes) cleave the bond between sequential NAM and NAG residues (Figure 1B). Muramidases are divided into two subgroups depending on their catalytic mechanism: lysozymes are hydrolytic enzymes that add water across the glycosidic bond during the cleavage generating a reducing NAM product; while lytic transglycosylases (LTs) catalyze an intramolecular rearrangement involving the C-6 hydroxyl group of the NAM resulting in the formation of unique 1,6-anhydro- $N$ acetylmuramic acid products, the so-called anhydromuropeptides (Holtje et al., 1975; Thunnissen et al., 1995; Callewaert and Michiels, 2010). PG peptidases can be classified into two groups: carboxypeptidases (removing the C-terminal amino acid of peptide stems) and endopeptidases (cleaving within the peptide cross-links), and both can be referred to as DD-, LD-, or DL-peptidases based on the isomeric form of the two amino acids that are split (Vollmer et al., 2008b).

PGHs are ubiquitous among all eubacteria (Shockman et al., 1996; Firczuk and Bochtler, 2007; Layec et al., 2008; Sharma et al., 2016). Many species present a large number of PG cleaving enzymes, and while for some of them, functional redundancy has been observed under laboratory conditions (van Heijenoort, 2011; Rolain et al., 2012; Singh et al., 2012), and specific functions have been demonstrated for others (Schaub et al., 2016; Santin and Cascales, 2017). During growth, PGHs are capable of fulfilling the PG-remodeling demands acting on the murein sacculus without disrupting the structural integrity of the cell wall, but a regulatory failure of their activity could easily lead to uncontrolled PG degradation and consequent cell lysis (autolysis) (van Heijenoort, 2011). Therefore, bacterial PGHs (so-called autolysins) must be regulated in order to prevent accidental lysis (Rice and Bayles, 2008). Regulation of bacterial PGH activity has been characterized at different levels including gene expression, subcellular localization, the formation of multi-enzyme catalytic complexes, or modification of the PG substrate (Holtje and Tuomanen, 1991; Vollmer et al., 2008b; Chapot-Chartier, 2010; Morlot et al., 2010).

The cleavage of covalent bonds in the murein sacculus during cell wall metabolism leads to the release of PG-derived material. Depending on the cleaving enzyme, different fragments can be released from the PG sacculus: both lysozymes and lytic transglycosylases release disaccharide-peptides, but while the hydrolytic reaction of lysozymes generates a terminal reducing NAM (Callewaert and Michiels, 2010), lytic transglycosylases produce anhydromuropeptides which present a 1,6-anhydro ring at the NAM (anhNAM) (Holtje et al., 1975); monosaccharide-peptides (named here muramyl peptides) can also be produced by the activity of $\mathrm{N}$-acetylglucosaminidases (Votsch and Templin, 2000). Even though peptidase or amidase activities do not release muropeptides or muramyl-peptides themselves, their role remodeling the high-molecular-weight murein sacculus or its soluble fragments (e.g., amidase activity releases NOD1-stimulatory free peptides) certainly shape the number and the chemical composition of the released molecules (Lenz et al., 2016).

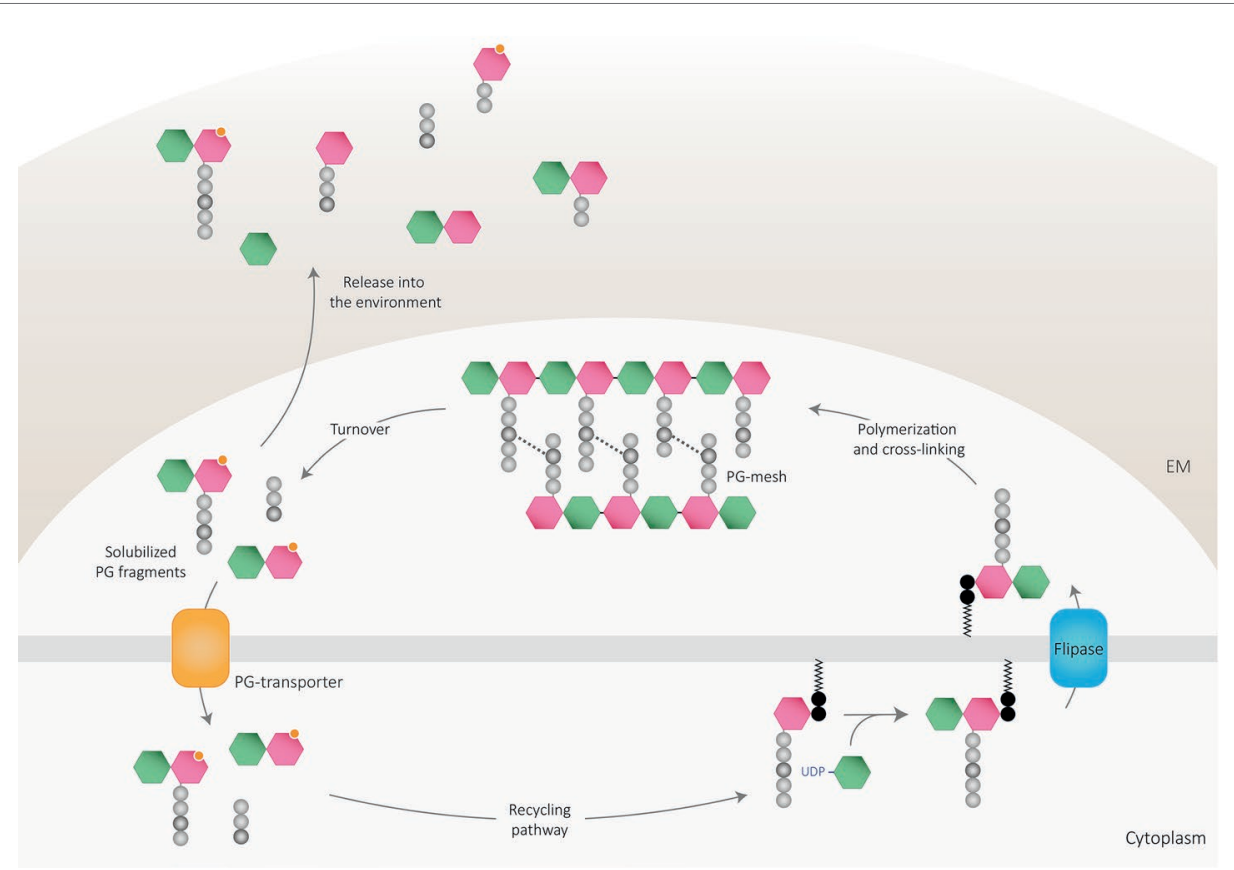

FIGURE 2 | Peptidoglycan recycling and muropeptide release. PG cleaving enzymes digest the sacculi delivering PG fragments to the periplasm, which can be either released to the environment or transported into the cytoplasm through PG transporters. Once in the cytosol, PG fragments might enter the recycling pathway to finally be reincorporated into the newly polymerized PG mesh or used as an own-energy source by the cell. Part of PG-turnover products is released to the environment, where are detected by other cells and can act as signaling molecules. EM: extracellular matrix. 
PG fragments are solubilized from the murein sacculus in active bacteria by a process termed cell wall turnover (Figure 2) that leads to the excision of muropeptides, shedding, and cell wall catabolism (Chaloupka, 1962; Doyle et al., 1988). As mentioned, up to half of the pre-existing PG is turned over and discharged from the wall every generation in both Gram-positive and Gram-negative bacteria (Mauck et al., 1971; Wong et al., 1974; Dworkin, 2014). The released material can be reimported into the bacterial cytoplasm and reused for PG synthesis or as nutrient or energy sources through an efficient PG recycling pathway (Chaloupka and Strnadova, 1972; Goodell and Schwarz, 1985; Park and Uehara, 2008; Borisova et al., 2016) or liberated to the environment. Accordingly, the bacterial PG recycling pathway modulates to some extent the bioavailability of soluble fragments (Johnson et al., 2013).

\section{PG Recycling}

Historically, it has been assumed that PG recycling was limited to Gram-negative bacteria since, in comparison, larger amounts of PG turnover products were isolated from the growth medium of several Gram-positives (Mauck et al., 1971). Nevertheless, orthologs of some recycling enzymes are present in most Gram-positive bacteria (Park and Uehara, 2008; Litzinger et al., 2010; Reith and Mayer, 2011). In fact, recent studies have shown that PG recycling also occurs in different Gram-positives (Borisova et al., 2016; Kluj et al., 2018), although reuse of PG sugars and peptide turnover products for murein synthesis in these organisms is currently unclear. PG recycling has been more extensively studied in Gram-negative bacteria (Johnson et al., 2013; Dhar et al., 2018) where recycling begins with degradation of the PG by the activity of PGHs. LTs are the main enzymes involved in high-molecular-weight sacculus degradation and therefore play a key role in PG recycling (Dominguez-Gil et al., 2016).

Most bacteria encode multiple LTs (e.g., 8 have been described in E. coli and 11 in $P$. aeruginosa), which can be divided into soluble periplasmic LTs (named Slts) or membrane-attached LTs (named Mlts), and can perform the cleavage at the end of the glycan strands (exolytic) and/or in the middle of the PG chains (endolytic) (Dik et al., 2017). Although redundancy in generating soluble anhydromuropeptides has been observed by single and multiple deletion analysis (Korsak et al., 2005; Lamers et al., 2015), a unique contribution from some hydrolytic enzymes has also been proven (Kraft et al., 1999). Particularly, Slt70 of E. coli is considered to be the major LT involved in PG-turnover, as it has been shown to be the main enzyme following $\beta$-lactam treatment (Cho et al., 2014).

Depending on the efficiency and regulation of the PG-recycling pathway of the bacterium, anhydromuropeptides can either be transported to the cytoplasm (where they are subsequently processed by the activity of several enzymes) or released to the environment by a currently unknown mechanism (Figure 2). In $E$. coli, the gate of entry for the internalization of soluble anhydromuropeptide monomers (NAG-anhNAM-peptides) into the cytoplasm is the AmpG permease, an inner transmembrane protein that specifically takes up anhydromuropeptides or free anhydrodisaccharides (Cheng and Park, 2002). Deletion of the gene encoding AmpG prevents the uptake of anhydromuropeptides leading to their accumulation in the medium (Jacobs et al., 1994; Wiedemann et al., 1998; Garcia and Dillard, 2008; Nyholm, 2009) revealing the importance of recycling as a limiting factor for PG-fragment release. Once in the cytosol, anhydromuropeptides are further hydrolyzed by a mechanism involving a set of dedicated enzymes (extensively reviewed in Johnson et al., 2013; Dhar et al., 2018). The specific activities of NagZ ( $N$-acetylglucosaminidase) and AmpD ( $N$-L-alanine amidase) on molecules presenting anhNAM structure yield NAG, anhNAM, and free peptides in the cytoplasm (Holtje et al., 1994; Cheng et al., 2000; Votsch and Templin, 2000; Lee et al., 2009). Resulting tetrapeptides are hydrolyzed by the action of the L,D-carboxypeptidase LdcA (Templin et al., 1999) into tripeptides, which can be degraded into individual amino acids for utilization as nutrient or energy sources (Schroeder et al., 1994; Schmidt et al., 2001; Uehara and Park, 2003) or attached directly to UDP-NAM by the murein peptide ligase Mpl (MenginLecreulx et al., 1996; Das et al., 2011). Ligated UDP-NAMtripeptides and processed sugar products can then be recycled by entering the pathway for de novo PG synthesis (White and Pasternak, 1967; Uehara et al., 2005, 2006).

The internalization of anhydromuropeptides and subsequent breakdown in order to supply a demanding nutrient or energy sources seems unlikely under favorable growth conditions (Uehara and Park, 2008), and even if enzymes involved in PG degradation are expressed during growth (Park and Uehara, 2008; Maqbool et al., 2012), it has been estimated that $97 \%$ of the recovered material is reutilized for new PG synthesis (Goodell, 1985). Furthermore, even if the switching control between PG recycling and catabolism is not clear yet, some genes encoding for enzymes involved in degradation of the peptide have been shown to be de-repressed under nutrient starvation (Shimada et al., 2013) pointing out a tight control between these two processes.

\section{Distribution and Function(s) of PG Recycling}

While PG turnover is widespread in bacteria, it remains unclear how prevalent PG recycling is. Since this pathway relies upon the transport of anhydromuropeptides into the cytosol, the existence of AmpG-like permeases may be required for PG recycling. Though PG recycling has only been experimentally proven in certain species, AmpG is present in diverse Gram-negatives (Uehara and Park, 2008) but apparently absent in Gram-positives (Reith and Mayer, 2011). This observation may fit with a limited number of known LTs in Gram-positives (Dik et al., 2017) and their apparently restricted function to PG enlargement (Tsui et al., 2016), spore formation/germination (Heffron et al., 2009), or induction of autolysis (Wydau-Dematteis et al., 2018). On the other hand, abundant lysozyme-like enzymes, $\mathrm{N}$-acetylglucosaminidases and amidases, have been described to act at the cell wall compartment in Gram-positive bacteria (Lopez et al., 1997; Smith et al., 2000; Vollmer and Bertsche, 2008). These activities liberate PG fragments 
presenting terminal-reducing NAM and free peptides, which can be taken up by other specific transporters, offsetting the lack of an AmpG permease (Reith and Mayer, 2011).

The presence of orthologs of other genes involved in the pathway also points toward the existence of a dedicated route for recycling PG-degradation products. In this regard, genes involved in the processing and reutilization of PG sugars are widespread among both Gram-negative and Gram-positive bacteria (Jaeger and Mayer, 2008; Borisova et al., 2014), suggesting an extensive role and consequently important function(s) of PG recycling. Though the primary function of PG recycling is not clear (it is not essential under experimental conditions) (Jacobs et al., 1994; Cheng et al., 2000), it has been reported to be involved in a range of diverse processes. It is still widely thought that reutilization of PG fragments as carbon and energy sources is potentially critical to promote growth under nutrientlimiting conditions, but for $E$. coli there is no clear evidence supporting this hypothesis. Nevertheless, reutilization of PG recycled products has been observed to be essential in particular cases. The use of recycled NAM for cell wall synthesis apparently increases survival of Bacillus subtilis and Staphylococcus aureus under starvation conditions during stationary phase (Borisova et al., 2016), which is consistent with previous findings showing that in Gram-positive bacteria MurQ and NagZ expression is higher in stationary phase (Litzinger et al., 2010; Botella et al., 2011). In the Gram-negative oral anaerobe Tannerella forsythia, which is unable to synthesize its own PG sugars, scavenging environmental muropeptides (released by cohabiting bacteria) through an AmpG-like transporter is vital for PG-synthesis (Ruscitto et al., 2017). Additionally, in two Cyanobacteria species, PG recycling has been suggested to be an energysaving strategy to promote growth under light-limiting conditions (Jiang et al., 2010).

Aside from the importance of the reutilization of PG products, other functions proposed for PG recycling are more related to the production and accumulation of solubilized cell wall fragments when the pathway is not working efficiently. In this regard, a variety of messenger functions have been attributed to PG fragments, which are compiled below.

\section{Alternative Ways to Produce Soluble PG Fragments}

The essentiality and uniqueness of the bacterial PG make this structure an excellent antibacterial target (Kohanski et al., 2010; Muller et al., 2017). It is therefore not surprising that lysozymes, which exhibit a highly specific cleavage activity on PG, are widespread (Callewaert and Michiels, 2010). Although the antimicrobial action of lysozymes is also intimately related to their structure (Ibrahim et al., 2001), their catalytic activity disrupts PG by hydrolyzing the $\beta-1,4$ glycosidic bonds linking adjacent PG monomers, resulting in cell lysis and successive release of muropeptides. Production of lysozymes constitutes a natural defence mechanism against bacterial pathogens (Bertsche et al., 2015), and consequently, pathogenic bacteria have developed different mechanisms to evade lysozyme action such as modification of the PG (Yadav et al., 2018), alteration of the charge, and strength of the envelope or the production of lysozyme inhibitors (Ragland and Criss, 2017).

As a defence mechanism, plants and animals have exploited PG structure and developed mechanisms to monitor the presence of bacteria through PG recognition proteins (PGRPs) (Royet et al., 2011; Gust, 2015), some of which also present PG-cleavage activity separate from their ability to sense bacterial PG (Royet and Dziarski, 2007; Royet et al., 2011). These PGRPs present $\mathrm{N}$-acetylmuramoyl-L-alanine amidase activity that hydrolyzes the amide bond between NAG and L-alanine in peptidoglycan and removes the stem peptides from the glycan chain, contributing to the release of PG fragments to the environment.

Furthermore, many Gram-negative bacteria can interact with other microbes and the host by releasing outer membrane vesicles (OMVs) to the environment (Kulp and Kuehn, 2010). Formation of OMVs has also been suggested as another mechanism of delivering peptidoglycan in several Gram-negative human pathogens (Kaparakis et al., 2010; Bielig et al., 2011).

\section{DETECTION OF RELEASED MUROPEPTIDES}

Specific roles for a variety of soluble PG fragments as messenger molecules have been known for decades (Adam and Lederer, 1984) and have come into focus more recently. Microbe-associated molecular patterns (MAMPs) are defined as molecular signatures highly conserved in bacteria but absent from the host cells (Boller and Felix, 2009). MAMPs are detected by specific receptors termed pattern recognition receptors (PRRs) that are able to bind PG among other molecules (including lipopolysaccharides, lipoteichoic acids, lipoproteins, microbial DNA and RNA, flagellin, fungal cell wall glucans, or chitin) (Strober et al., 2006; Cinel and Opal, 2009; Mogensen, 2009; Diacovich and Gorvel, 2010). In the host, MAMP recognition leads to the activation of PRR-induced signal pathways that trigger the expression of a broad range of molecules, including adaptor molecules, cytokines, chemokines, cell adhesion molecules, and immunoreceptors, which induce proinflammatory and antimicrobial responses (Akira et al., 2006).

Despite the abundance of PG-containing microbiota and the numerous studies implicating PG as an immunostimulatory signal (Boneca, 2005), little is known about the systemic concentration of PG fragments in the environment or host, even though it is well documented that muropeptides serve also as signaling molecules and that a collection of receptor systems have evolved to detect these molecules.

\section{PG Sensors}

In the last two decades, multiple structural motifs and proteins have been described to bind PG. Interestingly, not a single class of microorganism is sensed by only one type of receptor, hence ensuring a rapid and potent response while allowing for some specificity during, for example, infection. In this review, we summarize those receptors that recognize and bind $\mathrm{PG}$. 


\section{Lysin Motif}

LysM (LysM) is considered a general PG-binding domain that binds specifically to molecules containing repetitions of NAG such as chitin, peptidoglycan, and short oligosaccharides (Buist et al., 2008; Mesnage et al., 2014). The LysM, usually 42-48 amino acids in length, is an ubiquitous modular cassette present across all kingdoms except for Archaea (Zhang et al., 2009). Usually, multiple motifs within one LysM domain are separated by spacing sequences (typically Ser-Thr-Asp/Pro) forming a flexible region in-between (Buist et al., 2008; Ohnuma et al., 2008). While it was initially identified in bacterial cell wall degrading enzymes [e.g., E. coli lytic tranglycosylase MltD (Bateman and Bycroft, 2000), Enterococcus faecalis $N$-acetylglucosaminidase AtlA (Mesnage et al., 2014), B. subtilis D,L-endopeptidase CwlS (Wong et al., 2014), or Lactococcus lactic $N$-acetylglucosaminidase AcmA (Steen et al., 2005)], LysM is also present in many other proteins involved in PG synthesis or remodeling (Buist et al., 2008; Buendia et al., 2018). The study of several proteins involved in bacterial peptidoglycan synthesis and remodeling has shown that even when PG peptide stems are not necessary for LysM binding, they modulate the binding affinity (Mesnage et al., 2014). In plants, the recognition of PG by LysM containing proteins initiates a signaling cascade that can suppress the host immune response (Gust, 2015). Furthermore, several LysM-containing proteins have been described to be involved in diverse processes, including recognition of bacteria, during bacteria-plant symbiosis, bacteriophage infection, and assembly of bacterial spores (Andre et al., 2008; Buist et al., 2008; Zipfel, 2014; Gust, 2015; Dworkin, 2018).

\section{PASTA Domain}

Penicillin-binding and Ser/Thr kinase-associated (PASTA) proteins are essential tools for bacteria to sense and respond to the host environment and antibiotic stress as they play a central role in virulence and $\beta$-lactam resistance via their ability to regulate metabolism, cell division, and cell wall homeostasis through the recognition of muropeptides (Shah et al., 2008; Pensinger et al., 2018). The PASTA motif is involved in recognizing not only self-PG fragments but also exogenous muropeptides (Shah et al., 2008). Ligands are mostly species-specific, but a preference for muropeptides from species producing cell walls of similar composition (for example, containing $m \mathrm{DAP}$ in the third position in the peptide stem) has also been described (Lee et al., 2010; Mir et al., 2011).

\section{NOD-Like Receptors}

Nucleotide binding and oligomerization domain proteins (NODs) are intracellular regulatory proteins that respond to a variety of signaling molecules including PG-derived fragments (Girardin et al., 2003c; Martinon and Tschopp, 2005; McDonald et al., 2005; Dziarski and Gupta, 2006; Strober et al., 2006; Le Bourhis et al., 2007; Sorbara and Philpott, 2011; KeestraGounder and Tsolis, 2017). NLRs show a conserved architecture, containing a C-terminal leucine-rich repeat domain, a central nucleotide binding and oligomerization domain, and $\mathrm{N}$-terminal caspase activation and recruitment domain (Inohara and Nunez, 2003; Martinon and Tschopp, 2005). NOD1 and
NOD2 are the best characterized NLRs, so far. NOD1 recognizes molecules containing D-Glu-mDAP (including PG free, mono-, and disaccharide peptides) (Girardin et al., 2003a), which are primarily found in Gram-negative bacteria with some exceptions such as Bacillus spp., Mycobacterium sp., Listeria spp., and Lactobacillus plantarum (Girardin et al., 2003c; Bourhis et al., 2007; Mahapatra et al., 2008; Bernard et al., 2011), while NOD2 senses NAM-D-Ala-D-Glu unit, ubiquitously present in both Gram-positive and Gram-negative mono- and disaccharide di-, tri-, and tetrapeptides (Girardin et al., 2003b; Dagil et al., 2016). PG fragments from non-invasive bacteria are transported into the eukaryotic cytosol through bacterial secretion systems, endocytosis, or specific membrane transport systems [PEPT: PepT1, PepT2, and pannexin (Vavricka et al., 2004; Charrier and Merlin, 2006; Kanneganti et al., 2007; Swaan et al., 2008)] or are delivered via OMVs (Philpott et al., 2014; Kaparakis-Liaskos and Ferrero, 2015; Canas et al., 2018), where they are sensed by both NOD receptors. The detection of PG by NOD proteins results in the activation of intracellular signaling cascades that triggers the nuclear factor $-\kappa \mathrm{B}(\mathrm{NF}-\kappa \mathrm{B})$, innate response involved in inflammatory responses, and antimicrobial activity (Fritz et al., 2006; Meylan et al., 2006; Franchi et al., 2009).

\section{Peptidoglycan Recognition Proteins}

Peptidoglycan recognition proteins (PGRPs) are evolutionarily conserved innate immunity molecules homologous to bacteriophage type 2 amidases found in animals and humans that present bactericidal activity (Dziarski, 2004; Royet and Dziarski, 2007). All PGRPs have a carboxy-terminal amidase domain (named PGRP domain) with a specific binding site for muramyl penta-, tetra-, or tri-peptides (Royet and Dziarski, 2007), but some mammalian PGRPs also have an additional binding site specific for bacterial lipopolysaccharide (Tydell et al., 2006; Sharma et al., 2011). So far, diverse PGRPs have been identified in insects [e.g., Drosophila has 13 PGRPs (Royet et al., 2011; Kurata, 2014)] and mammals [e.g., humans and mice have four (PGLYRP 1-4) (Liu et al., 2000; Lu et al., 2006; Cho et al., 2007; Diziarski and Gupta, 2010)] that recognize diverse PG fragments depending on their affinity and have a function in antibacterial immunity and inflammation. Instead of activating the innate system, PGRPs directly kill bacterial cells by binding PG, either to muramyl-peptides exposed by lytic endopeptidases in Gram-positive bacteria or uniformly to the outer membrane in Gram-negative bacteria (Kashyap et al., 2017). PGRP-PG interaction activates bacterial two-component systems (CssR-CssS and CpxA-CpxRin in Gram-positive and Gram-negative bacteria, respectively) that induce bacterial lysis by membrane depolarization and the simultaneous induction of oxidative, thiol, and metal stresses, which produce bacterial killing (Royet et al., 2011; Kashyap et al., 2014, 2017). Some data also suggest that the amidase domain acts as a scavenger to degrade PG and control the immune response (Mellroth et al., 2003).

\section{C-Type Lectin-Like Receptors}

C-type lectin-like receptors (CTLRs) are a major class of PRR that present an extracellular carbohydrate recognition domain that putatively binds sugar moieties within the glycan backbone 
of bacterial PG or the fungal glucan mannan, in a calciumdependent manner (Plato et al., 2013; Sukhithasri et al., 2013). Upon ligand recognition, specialized CTLRs trigger or inhibit a variety of signaling pathways, thus initiating pathogen phagocytosis, cytokine production, and activating diverse immune responses (Mayer et al., 2017). CTLRs bind to various pathogens, including viruses, fungi, parasites, and bacteria, and little is known about their specific role (if any) in PG detection. Regenerating gene family protein $3 \mathrm{~A}$ (Reg3A) and mannose-binding lectin (MBL) protein are the only ones proven so far to bind PG (Sukhithasri et al., 2013). Reg3A is a lectin family protein that recognizes bacterial PG and presents bactericidal activity against Gram-positive bacteria (Lehotzky et al., 2010; van Ampting et al., 2012), while MBL is an oligomeric, calcium-dependent serum protein that recognizes both bacterial and fungal cell wall components leading to the activation of the lectin complement pathway (Shi et al., 2004; Nadesalingam et al., 2005).

\section{Hexokinases}

Known as the first enzyme involved in glycolysis that catalyzes the phosphorylation of glucose to glucose-6-phosphate, hexokinases are also eukaryotic cytosolic sensors for PG. Recently, it has been suggested that the monomeric sugar NAG, generated during PG hydrolysis, can trigger the activation of the inflammatory programs in immune cells through binding and dissociating the cytosolic hexokinase (Gerriets et al., 2015; Wolf et al., 2016). Active hexokinases are associated with the mitochondrial outer membrane but are released when inhibited by NAG, similar to when glucose-6-phosphate (the product of hexokinase) accumulates the cytosol and promotes activation of the NLRP3 inflammasome, which regulates the processing and secretion of interleukin (IL)-1b and IL-18 (Shimada et al., 2010). Although the mechanism by which this occurs has not yet been described, a model has been proposed in which hexokinase acts as a pattern recognition receptor, alerting the cell to the degradation of bacterial PG in phagosomes and activating an inflammatory response via disruption of the glycolytic pathway and the mitochondrial function (Wolf et al., 2016).

\section{MECHANISMS TO AVOID PG RECOGNITION}

Bacteria have evolved sophisticated molecular strategies to subvert host defences by interfering with molecules involved in pathogen recognition and signaling. Both pathogenic and commensal bacteria are able to modify their PG in order to change the interaction with receptors and therefore avoid triggering the host immune responses (Boneca, 2005; Davis and Weiser, 2011). PG modifications fall into two main groups: (1) modification of glycan backbone to resist catalytic activity of PG-hydrolytic enzymes ( $N$-deacetylation, $\mathrm{N}$-glycolylation, $\mathrm{O}$-acetylation) and (2) modifications of the stem peptides to evade immune recognition (L-Ala peptide substitutions, D-Glu and mDAP amidation, and mDAP substitution by L-ornithine). Thus, these modifications constitute a tactic that provides resistance to cell lysis and helps bacteria to evade the host immune system. For specificities about PG modifications, we refer to excellent reviews on the topic (Moynihan et al., 2014; Ragland and Criss, 2017; Yadav et al., 2018).

\section{MUROPEPTIDES AS SIGNALING MOLECULES}

PG remodeling produces soluble PG fragments that can have a role in bacteria-bacteria and bacteria-host communication and act as signaling molecules that trigger adaptive responses (Figure 3, Table 1).

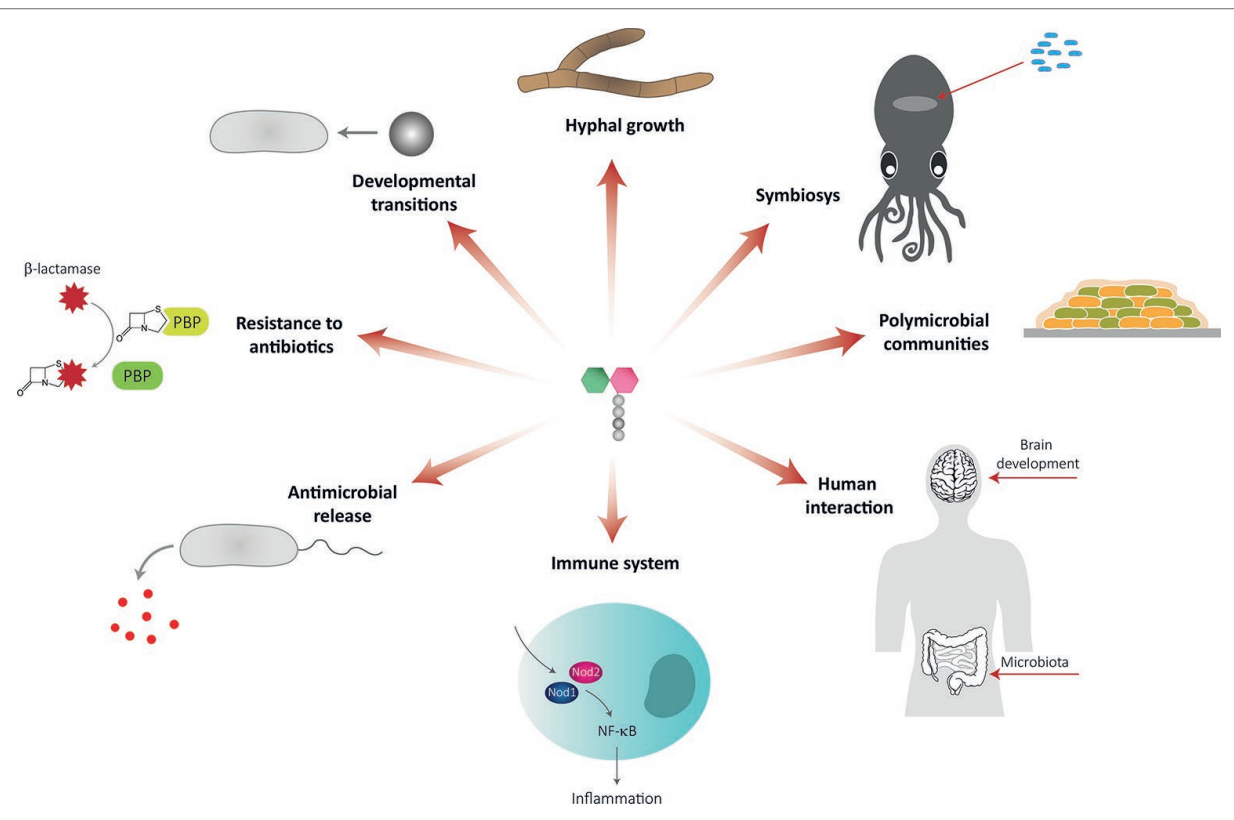

FIGURE 3 | Muropeptides as signaling molecules. 
TABLE 1 | Messenger functions of muropeptides.

\begin{tabular}{|c|c|c|c|}
\hline PG fragment & Structure & Sensing molecule & Function \\
\hline \multirow[t]{2}{*}{ Dissacharide tripeptide } & & \multirow{2}{*}{$\begin{array}{l}\text { PrkC and homologs } \\
\text { (STPKs) }\end{array}$} & Induction of germination (Shah et al., 2008; Dworkin and Shah, 2010) \\
\hline & & & Exit from dormancy (Keep et al., 2006; Mukamolova et al., 2006) \\
\hline Monomeric NAG sugar & & Ngt1 & Hyphal growth induction (Alvarez and Konopka, 2007) \\
\hline Muramyl-dipeptide & & Cyr1p & Hyphal growth induction (Xu et al., 2008) \\
\hline \multirow{3}{*}{$\begin{array}{l}\text { Anhydro-murotetrapeptide } \\
\text { (Tracheal cytotoxin, TCT) }\end{array}$} & & NA & Signaling for morphogenesis (Koropatnick et al., 2004) \\
\hline & & PGRP2 & Hydrolysis of pro-inflammatory PG fragments (Troll et al., 2010) \\
\hline & & PGRP3-4 & Induction of inflammatory response (Goodson et al., 2005) \\
\hline
\end{tabular}

Anhydro-muramyltripeptide AmpR $\quad$-Lactamase induction: AmpC (Uehara and Park, 2002, 2008)

\begin{tabular}{|c|c|c|}
\hline Disaccharide pentapeptide & $\mathrm{BlrB}$ & $\beta$-Lactamase induction: Amp, Cep, Imi (Tayler et al., 2010) \\
\hline $\begin{array}{l}\text { Dipeptide D-Glu-mDAP } \\
\text { (mono and disaccharide peptides } \\
\text { containing this structure) }\end{array}$ & NOD1 & NF-кB Innate response activation (Girardin et al., 2003a,b) \\
\hline
\end{tabular}

\section{Muramyl-dipeptide} (disaccharide di-, tri-, tetrapeptides)

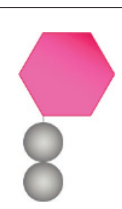

NF-кB Innate response activation (Fritz et al., 2006; Meylan et al., 2006; Franchi et al., 2009) 


\section{Developmental Transitions}

Many bacteria have sophisticated mechanisms to undergo morphological changes in response to environmental stress including the formation of spores, dormant cells, persisters, or viable but non-culturable cells (Oliver, 2005; Wood et al., 2013; Li et al., 2014; Huang and Hull, 2017). Cells in these states monitor their environment seeking for improved conditions to reverse non-active states and reinitiate growth. Taking into account the quantity of PG release by bacteria (Doyle et al., 1988), it is plausible that muropeptides play a role as interspecies signal molecules to promote microbial growth under favorable conditions (Keep et al., 2006).

For example, B. subtilis spores are able to germinate in the presence of low concentration of muropeptides (disaccharide tripeptides containing $m \mathrm{DAP}$ ) released by actively growing cells (Shah et al., 2008; Dworkin and Shah, 2010). Muropeptidedriven exit from dormancy requires the PrkC kinase, a member of the serine/threonine kinase (STPK) family, which has an intracellular kinase domain and an extracellular PG binding domain with multiple PASTA repeats (Yeats et al., 2002; Squeglia et al., 2011). PrkC binds PG, initiating a signal cascade that leads to spore germination (Shah et al., 2008). STPKs have a variety of roles in bacteria and are found in most Gram-positive bacteria. To date, PrkC homologues have been identified in S. pneumoniae (StkP), S. mutans ( $\mathrm{PknB}$ ), M. tuberculosis ( $\mathrm{PknB})$, C. difficile (PrkC), and S. aureus (PknB) (Fernandez et al., 2006; Sebaihia et al., 2006; Donat et al., 2009; Maestro et al., 2011; Mir et al., 2011). Interestingly, S. aureus PknB homolog responds not only to mDAP PG-type but also to the L-Lys-containing muropeptides (Dworkin and Shah, 2010), suggesting that bacteria expressing this kinase can react to signals from all species that produce PG.

Muropeptides are also implicated in the exit from dormancy of Micrococcus and Mycobacterium through the resuscitationpromoting factor (Rpf), a muralytic enzyme that cleaves the $\beta-1,4$ glycosidic bond in the glycan backbone of PG (Mukamolova et al., 2002, 2006). Combined with other hydrolytic enzymes, Rpfs might generate $m$ DAP-containing muropeptides, which can bind to STPKs and trigger resuscitation in an analogous manner to spore germination in B. subtilis (Shah et al., 2008; Kana and Mizrahi, 2010). Furthermore, these $m$ DAP-muropeptides might be detected by other receptors like Nod1 (Girardin et al., 2003a,c), suggesting that mycobacteria may, in addition, utilize those to modulate host innate immune responses during infection (Jo, 2008).

The predatory bacterium Myxococcus xanthus is able to respond to prey signals and alter its chemotactic and developmental pattern by forming fruiting bodies, where the vegetative cell differentiates into spores (Berleman et al., 2006; Keane and Berleman, 2016). One key phenomenon during fruiting body formation is the establishment of rhythmically advancing waves of cells (known as rippling) that has been shown to be induced by PG (Shimkets and Kaiser, 1982). This behavior is stimulated not only by $M$. xanthus PG fragments but also by a variety of proteobacteria and Gram-positive bacteria PG (e.g., E. coli, B. subtilis) (Shimkets and Kaiser, 1982).

Altogether, these findings suggest a pathway for bacterial resuscitation from a non-growing state via the detection of cell wall fragments in the environment, which seems to be a widely used strategy in the microbial world (Keep et al., 2006).

\section{Interspecies Interactions}

PG fragments serve as signals in a range of host interactions (both pathogenic and symbiotic relationship of bacteria with plants and animals) and also in prokaryote-prokaryote encounters. For example, Bacillus cereus mediates commensalism with bacteria from the Cytophaga-Flavobacterium group in the soybean rhizosphere (Peterson et al., 2006). PG isolated from $B$. cereus stimulates the growth of Flavobacterium johnsoniae in vitro, pointing out to a beneficial relationship between these rhizosphere microorganisms. It has been suggested that $F$. johnsoniae secretes a cell wall degrading enzyme that permits the mobilization of $B$. cereus PG fragments as a carbon source for their growth, although the responsible enzyme and mechanism are still unknown (Peterson et al., 2006).

In C. albicans, muramyl dipeptides exhibit a potent hyphainducing activity by directly binding to adenylyl cyclase Cyrlp LRR domain that stimulates cAMP production and subsequent hyphal growth (Xu et al., 2008). In addition, when C. albicans undergoes hyphal morphogenesis as a response to the presence of PG, $P$. aeruginosa is able to form a dense biofilm on the filamentous hyphal cells and kill them. Interestingly, C. albicans has developed a mechanism to protect itself by responding to the quorum factor 3-oxo-C12 homoserine lactone produced by Pseudomonas, which restricts its growth to a budding pattern that is not attacked by the bacteria (Hogan and Kolter, 2002; Naseem et al., 2012).

There are also several examples of PG fragments triggering the production of antimicrobial compounds within bacterial communities. P. aeruginosa is found in acute and chronic wounds forming a biofilm resistant to antimicrobials. Recent studies proved that exogenous NAG and other PG fragments derived from commensal Gram-positive bacteria elevate the virulence of $P$. aeruginosa, which is able to respond to the presence of PG fragments by producing pyocyanin, a potent antimicrobial phenazine (Korgaonkar and Whiteley, 2011; Korgaonkar et al., 2013). As Pseudomonas lives in polymicrobial communities, this mechanism might be of advantage to monitor surrounding microorganisms in order to eliminate competitors or provide additional nutrients for growth. In a similar way, NAG also induces the production of antimicrobials in the soil bacterium Streptomyces coelicolor (Rigali et al., 2006).

Another pathogenic bacterium, E. coli, also responds to NAG molecules derived from PG degradation by reducing CURLI fibers and type 1 fimbriae synthesis, both being essential for pathogenesis (Konopka, 2012; Naseem et al., 2012). In this case, regulation of these bacterial structures could balance the interaction between the pathogen and the host immune response, delaying the inflammation and allowing the dissemination of the bacteria within the host.

\section{Induction of Antibiotic Resistance}

Some bacteria are able to induce $\beta$-lactamases expression in the presence of high levels of antibiotics (e.g., Citrobacter freundii, P. aeruginosa, and Stenotrophomonas), a phenomenon that is 
tightly linked to PG recycling (Dietz et al., 1997b; Zeng and Lin, 2013; Yin et al., 2014). In Gram-negative bacteria, two major mechanisms have been characterized: the AmpG-AmpRAmpC pathway and the BlrAB two-component system. Regulation of the $\beta$-lactamase AmpC relies on the relative concentrations of cytoplasmic anhydromuropeptides. In the absence of $\beta$-lactam pressure, the UDP-muramyl-pentapeptide PG precursor is bound to the transcriptional regulator AmpR, inhibiting the expression of the ampC gene (Jacoby, 2009). However, in the presence of $\beta$-lactams, PG synthesis is blocked due to the inhibition of PBPs transpeptidase activity (Moya et al., 2009; Cho et al., 2014) leading to dysfunctionality of PBPs and resulting in an accumulation of anhydromuropeptides (mainly anhydromuramyl-tripeptides) in the periplasm (Cho et al., 2014). This accumulation displaces UDP-muramyl-pentapeptide from AmpR (Uehara and Park, 2002, 2008), and thus, ampC is expressed and $\beta$-lactamases are secreted to the periplasm, where they hydrolyze the antibiotic (Holtje et al., 1994; Jacobs et al., 1994; Jacobs, 1997; Dietz et al., 1997a). Similarly, in S. aureus and Bacillus licheniformis, accumulation of cytoplasmic dipeptides, D-Glu-L-Lys or D-Glu-mDAP, respectively, is responsible for triggering the inactivation of $\mathrm{BlaI} / \mathrm{MecI}$ repressors, leading to the synthesis of $\beta$-lactamases BlaZ, BlaP, and MecA (Amoroso et al., 2012). In Aeromonas hydrophila, $\beta$-lactamase production is regulated by a different system in which expression of AmpC is controlled through the two-component system BlrAB. Upon $\beta$-lactam exposure, disaccharide pentapeptides accumulate in the periplasm, inducing the autophosphorylation of $\mathrm{BlrB}$, which phosphorylates BlrA, activating the transcription of the AmpC, Cep, and Imi $\beta$-lactamases simultaneously (Tayler et al., 2010). Additionally, the BlrAB two-component system (also known as CreBC) has been associated with $\beta$-lactam resistance in $P$. aeruginosa and Stenotrophomonas maltophilia (Moya et al., 2009; Huang et al., 2015).

In the past years, the use of combination therapy with $\beta$-lactams and vancomycin to treat methicillin-resistant Staphylococcus aureus (MRSA)-infected patients has caused the emergence of $\beta$-lactam-induced vancomycin-resistant MRSA (BIVR-MRSA). The presence of $\beta$-lactams inhibits PG biosynthesis, producing the accumulation of large amounts of PG precursors (specifically lipid II) with free D-Ala-D-Ala terminals that bind with vancomycin, depleting its concentration. Even if it is well characterized that the muropeptide NAGNAM-L-Ala-D-Gln-L-Lys-( $\varepsilon$-amino-4Gly)-D-Ala-2Gly triggers vancomycin resistance (Ikeda et al., 2010), the mechanism underlying BIVR phenomenon remains to be elucidated.

Though induction mechanisms differ, all mentioned pathways are controlled by the amount of soluble PG fragments and so are linked to cell wall turnover and PG recycling.

\section{BACTERIA-HOST INTERACTIONS}

The interaction of bacteria with host cells through PG signaling molecules is well known, and the PG-mediated responses have been characterized in the past years. In mammals, plants, and some insects, PG-derived fragments are recognized by the innate immune system and promote host defence against bacterial infections (Royet et al., 2011; Gust, 2015; Capo et al., 2016; Pashenkov et al., 2018; Wolf and Underhill, 2018), indicating that PG recognition is an evolutionarily conserved process.

PG is involved in establishing symbiosis during Vibrio fischeri colonization of the Euprymna scolopes squid light organ (Koropatnick et al., 2004). In this marine mutualism, the squid uses light produced by $V$. fischeri to avoid predators during its nocturnal behavior. Juvenile squids make use of the ciliated epithelial cells in the light organ to acquire the $V$. fischeri symbiont from the environment in each generation. Bacterial cells swim through ciliated ducts to gain access to deep crypt spaces, where they lose the flagellum and establish a permanent association with the host. Once colonized, $V$. fischeri releases tracheal cytotoxin (TCT, 1,6-anhydro-disaccharide tetrapeptides containing $m \mathrm{DAP}$ ), which in synergy with LPS derivatives triggers the normal morphogenesis of the light organ. Morphogenesis involves the loss of ciliated epithelium, the shortening and eventual loss of appendages (Koropatnick et al., 2004, 2007; Brennan et al., 2014), and the reduction of mucus secretion (Nyholm et al., 2000), which prevents the entry of other bacteria. E. scolopes has four known PGRPs that are expressed in the light organ, which could be responsible for TCT sensing (Goodson et al., 2005; Royet et al., 2011). PGRP3 and PGRP4 are proposed to function as PG receptors on the surface of light organ cells, while PGRP2 is thought to be secreted into the lumen of the crypts helping maintain an appropriate level of $V$. fischeri. PGRP2 also hydrolyzes PG fragments preventing the inflammatory response activation, which allows the beneficial coexistence of the symbiont with the host (Troll et al., 2010).

The two Gram-negative pathogens Neisseria gonorrhoeae and Bordetella pertussis also release high amounts of muropeptides during infection: a mixture of 1,6-anhydrodisaccharide tri- and tetrapeptides (Sinha and Rosenthal, 1980, 1981) and TCT (Rosenthal et al., 1987), respectively. PG fragments are sensed by the intracellular NOD1 and NOD2 proteins that trigger the NF- $\kappa \mathrm{B}$ and the mitogen-activated protein kinase pathways, finally stimulating the activation of the innate immune response, the release of proinflammatory cytokines, and cell damage. In $B$. pertussis infection, the release of TCT causes the death and detachment of ciliated cells from the epithelium of the trachea (Goldman et al., 1982; Heiss et al., 1993), while a similar pathology is observed during gonococcal infection of human fallopian tubes (Melly et al., 1984; Woodhams et al., 2013; Chan and Dillard, 2017). Likewise, detection of PG fragments of other pathogens (e.g., Shigella spp.) by NOD proteins can stimulate the innate immune response too (Philpott et al., 2000; Girardin et al., 2001; Nigro et al., 2008).

Moreover, it has been proposed that in humans, PG fragments might present other signaling functions apart from modulating the inflammatory response. Aside from defending the host against pathogens, the immune system is also involved in accommodating host colonization by symbiotic microorganisms and maintaining microbiota-host homeostasis. PG fragments are therefore part of the mechanism that controls interactions between the microbiota and host and has effects on host 
physiology and development outside the gastrointestinal system (Royet et al., 2011). Gut microbiota is a source of PG that can be translocated from the intestinal mucosa into circulation in the absence of pathogens (Clarke et al., 2010).

For example, recent studies strongly suggest that PG fragments from the intestinal microbiota have the potential to affect the immune system and govern the inflammatory response through NOD proteins (Hergott et al., 2016). In a similar way, and even though the underlying mechanisms remain to be elucidated, gut microbiota has been proposed to modulate brain development and behavior. PG fragments derived from commensal gut microbiota can be translocated into the brain by crossing the blood-brain barrier and can induce inflammation (Fillon et al., 2006; Arentsen et al., 2017). During mice brain development, PG fragments are sensed by pattern recognition receptors (PRRs) expressed during a specific temporal window, in concordance with the PG accumulation observed in the cerebellum and in parallel with the bacterial colonization process (Arentsen et al., 2017). Interestingly, any perturbation of the gut microbiota (e.g., antibiotic treatment) alters the expression of those PRRs in the brain, suggesting that this disruption may alter the developing brain, making it more susceptible to disorders or increasing the risk for immune diseases (Arentsen et al., 2017, 2018). Still, little is known about the structure of the PG molecule that generates these effects or the mechanism behind it.

Finally, somnogenic activity has been attributed to some PG fragments derived from gut microbiota, such as muramyl peptides containing DAP (Krueger, 1985; Krueger and Opp, 2016). According to the reported data, this somnogenic property is structure-dependent, with muramyl-tripeptide being the smallest active molecule able to induce sleep.

\section{CONCLUSIONS}

The role of PG as a MAMP has long been recognized, especially as signaling molecules that modulate the innate immune response in some animals and plants. As during normal cell growth, bacteria release PG turnover products to the environment, and different organisms have developed sophisticated mechanisms to detect and respond to these molecules. Besides their role in infection or immune response development, bacteria use PG fragments as signaling cues to track the state of their cell wall or to monitor surrounding microorganisms. As many bacteria live within polymicrobial communities, this might be a

\section{REFERENCES}

Adam, A., and Lederer, E. (1984). Muramyl peptides: immunomodulators, sleep factors, and vitamins. Med. Res. Rev. 4, 111-152. doi: 10.1002/ med.2610040202

Akira, S., Uematsu, S., and Takeuchi, O. (2006). Pathogen recognition and innate immunity. Cell 124, 783-801. doi: 10.1016/j.cell.2006.02.015

Alvarez, F. J., and Konopka, J. B. (2007). Identification of an $\mathrm{N}$-acetylglucosamine transporter that mediates hyphal induction in Candida albicans. Mol. Biol. Cell. 18, 965-975. doi: 10.1091/mbc.E06-10-0931 beneficial mechanism to eliminate competitors or to obtain additional nutrients for growth. As a result of these functions, PG-fragments can be considered as signaling molecules.

The amount of PG turnover products released to the environment is dependent on the PG recycling pathway, and so, it is expected that bacteria regulate this process. Information regarding the regulation of $\mathrm{AmpG}$ or other transporters with similar activity is therefore crucial for a complete understanding of the function(s) of released anhydromuropeptides and other PG fragments; however, few studies have focused on this kind of protein (Cheng and Park, 2002; Chahboune et al., 2005; Zhang et al., 2010; Chan and Dillard, 2016; Li et al., 2016). A recently described assay to quantify AmpG-mediated transport (Perley-Robertson et al., 2016) may help to understand important aspects regarding the regulation of this permease in years to come. Likewise, other interesting tools have recently been developed to investigate PG recycling by studying other enzymes involved in this pathway (DeMeester et al., 2018).

The development of highly sensitive analytical methods and the use of synthetic muropeptides could help to elucidate the specific receptors that are able to bind PG as much as to determine the agonist PG structures and their role as signaling molecules. Overall, PG sensing seems to be a global mechanism that leads to different responses, so it is conceivable the existence of multiple PG-sensing pathways. More research is needed to clarify the different sensing mechanisms, to determine the interplay level of the different receptors (or to identify new ones), or understand the responses generated by muropeptides during bacteria-bacteria or bacteria-host interactions.

\section{AUTHOR CONTRIBUTIONS}

All authors listed have made a substantial, direct and intellectual contribution to the work, and approved it for publication.

\section{FUNDING}

OI and $\mathrm{SH}$ are thankful to the Swedish Research Council, Laboratory for Molecular Infection Medicine Sweden (MIMS) and UCMR for the financial support. Research in the Cava lab was supported by MIMS, the Knut and Alice Wallenberg Foundation (KAW), the Swedish Research Council, and the Kempe Foundation. 
Arentsen, T., Qian, Y., Gkotzis, S., Femenia, T., Wang, T., Udekwu, K., et al. (2017). The bacterial peptidoglycan-sensing molecule Pglyrp2 modulates brain development and behavior. Mol. Psychiatry 22, 257-266. doi: 10.1038/mp.2016.182

Bateman, A., and Bycroft, M. (2000). The structure of a LysM domain from E. coli membrane-bound lytic murein transglycosylase D (MltD). J. Mol. Biol. 299, 1113-1119. doi: 10.1006/jmbi.2000.3778

Berleman, J. E., Chumley, T., Cheung, P., and Kirby, J. R. (2006). Rippling is a predatory behavior in Myxococcus xanthus. J. Bacteriol. 188, 5888-5895. doi: 10.1128/JB.00559-06

Bernard, E., Rolain, T., Courtin, P., Hols, P., and Chapot-Chartier, M. P. (2011). Identification of the amidotransferase AsnB1 as being responsible for mesodiaminopimelic acid amidation in Lactobacillus plantarum peptidoglycan. J. Bacteriol. 193, 6323-6330. doi: 10.1128/JB.05060-11

Bertsche, U., Mayer, C., Gotz, F., and Gust, A. A. (2015). Peptidoglycan perception-sensing bacteria by their common envelope structure. Int. J. Med. Microbiol. 305, 217-223. doi: 10.1016/j.ijmm.2014.12.019

Bielig, H., Rompikuntal, P. K., Dongre, M., Zurek, B., Lindmark, B., Ramstedt, M., et al. (2011). NOD-like receptor activation by outer membrane vesicles from Vibrio cholerae non-O1 non-O139 strains is modulated by the quorumsensing regulator HapR. Infect. Immun. 79, 1418-1427. doi: 10.1128/IAI.00754-10

Boller, T., and Felix, G. (2009). A renaissance of elicitors: perception of microbeassociated molecular patterns and danger signals by pattern-recognition receptors. Annu. Rev. Plant Biol. 60, 379-406. doi: 10.1146/annurev. arplant.57.032905.105346

Boneca, I. G. (2005). The role of peptidoglycan in pathogenesis. Curr. Opin. Microbiol. 8, 46-53. doi: 10.1016/j.mib.2004.12.008

Borisova, M., Gaupp, R., Duckworth, A., Schneider, A., Dalugge, D., Muhleck, M., et al. (2016). Peptidoglycan recycling in gram-positive bacteria is crucial for survival in stationary phase. MBio 7, 1-10. doi: 10.1128/mBio.00923-16

Borisova, M., Gisin, J., and Mayer, C. (2014). Blocking peptidoglycan recycling in Pseudomonas aeruginosa attenuates intrinsic resistance to fosfomycin. Microb. Drug Resist. 20, 231-237. doi: 10.1089/mdr.2014.0036

Botella, E., Hubner, S., Hokamp, K., Hansen, A., Bisicchia, P., Noone, D., et al. (2011). Cell envelope gene expression in phosphate-limited Bacillus subtilis cells. Microbiology 157, 2470-2484. doi: 10.1099/mic.0.049205-0

Boudreau, M. A., Fisher, J. F., and Mobashery, S. (2012). Messenger functions of the bacterial cell wall-derived muropeptides. Biochemistry 51, 2974-2990. doi: 10.1021/bi300174x

Bourhis, L. L., Benko, S., and Girardin, S. E. (2007). Nod1 and Nod2 in innate immunity and human inflammatory disorderss. Biochem. Soc. Trans. 35, 1479-1784. doi: 10.1042/BST0351479

Brennan, C. A., Hunt, J. R., Kremer, N., Krasity, B. C., Apicella, M. A., McFallNgai, M. J., et al. (2014). A model symbiosis reveals a role for sheathedflagellum rotation in the release of immunogenic lipopolysaccharide. elife 3:e01579. doi: 10.7554/eLife.01579

Buendia, L., Girardin, A., Wang, T., Cottret, L., and Lefebvre, B. (2018). LysM receptor-like kinase and LysM receptor-like protein families: an update on phylogeny and functional characterization. Front. Plant Sci. 9:1531. doi: 10.3389/fpls.2018.01531

Buist, G., Steen, A., Kok, J., and Kuipers, O. P. (2008). LysM, a widely distributed protein motif for binding to (peptido)glycans. Mol. Microbiol. 68, 838-847. doi: 10.1111/j.1365-2958.2008.06211.x

Callewaert, L., and Michiels, C. W. (2010). Lysozymes in the animal kingdom. J. Biosci. 35, 127-160. doi: 10.1007/s12038-010-0015-5

Canas, M. A., Fabrega, M. J., Gimenez, R., Badia, J., and Baldoma, L. (2018). Outer membrane vesicles from probiotic and commensal Escherichia coli activate NOD1-mediated immune responses in intestinal epithelial cells. Front. Microbiol. 9:498. doi: 10.3389/fmicb.2018.00498

Capo, F., Charroux, B., and Royet, J. (2016). Bacteria sensing mechanisms in Drosophila gut: local and systemic consequences. Dev. Comp. Immunol. 64, 11-21. doi: 10.1016/j.dci.2016.01.001

Cava, F., and de Pedro, M. A. (2014). Peptidoglycan plasticity in bacteria: emerging variability of the murein sacculus and their associated biological functions. Curr. Opin. Microbiol. 18, 46-53. doi: 10.1016/j.mib.2014.01.004

Chahboune, A., Decaffmeyer, M., Brasseur, R., and Joris, B. (2005). Membrane topology of the Escherichia coli AmpG permease required for recycling of cell wall anhydromuropeptides and AmpC beta-lactamase induction. Antimicrob. Agents Chemother. 49, 1145-1149. doi: 10.1128/AAC.49.3.1145-1149.2005
Chaloupka, J., Kreckova, P., and Rihova, L. (1962). The mucopeptide turnover in the cell walls of growing cultures of Bacillus megaterium KM. Experientia 18, 362-363. doi: 10.1007/BF02172250

Chaloupka, J., and Strnadova, M. (1972). Turnover of murein in a diaminopimelic acid dependent mutant of Escherichia coli. Folia. Microbiol. 17, 446-455. doi: $10.1007 / \mathrm{BF} 02872729$

Chan, J. M., and Dillard, J. P. (2016). Neisseria gonorrhoeae crippled its peptidoglycan fragment permease to facilitate toxic peptidoglycan monomer release. J. Bacteriol. 198, 3029-3040. doi: 10.1128/JB.00437-16

Chan, J. M., and Dillard, J. P. (2017). Attention seeker: production, modification, and release of inflammatory peptidoglycan fragments in Neisseria species. J Bacteriol. 199, 1-13. doi: 10.1128/JB.00354-17

Chapot-Chartier, M.-P. (2010). "Bacterial autolysins," in Prokaryotic cell wall compounds: Structure and biochemistry. eds. H. König, H. Claus, and A. Varma (Berlin, Heidelberg: Springer Berlin Heidelberg), 383-406.

Charrier, L., and Merlin, D. (2006). The oligopeptide transporter hPepT1: gateway to the innate immune response. Lab. Investig. 86, 538-546. doi: 10.1038/labinvest.3700423

Cheng, Q., Li, H., Merdek, K., and Park, J. T. (2000). Molecular characterization of the beta-N-acetylglucosaminidase of Escherichia coli and its role in cell wall recycling. J. Bacteriol. 182, 4836-4840. doi: 10.1128/ JB.182.17.4836-4840.2000

Cheng, Q., and Park, J. T. (2002). Substrate specificity of the AmpG permease required for recycling of cell wall anhydro-muropeptides. J. Bacteriol. 184. 6434-6436. doi: 10.1128/JB.184.23.6434-6436.2002

Cho, H., Uehara, T., and Bernhardt, T. G. (2014). Beta-lactam antibiotics induce a lethal malfunctioning of the bacterial cell wall synthesis machinery. Cell 159, 1300-1311. doi: 10.1016/j.cell.2014.11.017

Cho, S., Wang, Q., Swaminathan, C. P., Hesek, D., Lee, M., Boons, G. J. et al. (2007). Structural insights into the bactericidal mechanism of human peptidoglycan recognition proteins. Proc. Natl. Acad. Sci. USA 104, 8761-8766. doi: 10.1073/pnas.0701453104

Cinel, I., and Opal, S. M. (2009). Molecular biology of inflammation and sepsis: a primer. Crit. Care Med. 37, 291-304. doi: 10.1097/CCM.0b013e31819267fb

Clarke, T. B., Davis, K. M., Lysenko, E. S., Zhou, A. Y., Yu, Y., and Weiser, J. N. (2010). Recognition of peptidoglycan from the microbiota by Nodl enhances systemic innate immunity. Nat. Med. 16, 228-231. doi: 10.1038/nm.2087

Dagil, Y. A., Arbatsky, N. P., Alkhazova, B. I., L’Vov, V. L., Mazurov, D. V., and Pashenkov, M. V. (2016). The dual NOD1/NOD2 agonism of muropeptides containing a meso-diaminopimelic acid residue. PLoS One 11:e0160784. doi: 10.1371/journal.pone.0160784

Das, D., Herve, M., Feuerhelm, J., Farr, C. L., Chiu, H. J., Elsliger, M. A., et al. (2011). Structure and function of the first full-length murein peptide ligase (Mpl) cell wall recycling protein. PLoS One 6:e17624. doi: 10.1371/ journal.pone.0017624

Davis, K. M., and Weiser, J. N. (2011). Modifications to the peptidoglycan backbone help bacteria to establish infection. Infect. Immun. 79, 562-570. doi: 10.1128/IAI.00651-10

de Pedro, M. A., and Cava, F. (2015). Structural constraints and dynamics of bacterial cell wall architecture. Front. Microbiol. 6:449. doi: 10.3389/ fmicb.2015.00449

DeMeester, K. E., Liang, H., Jensen, M. R., Jones, Z. S., D’Ambrosio, E. A., Scinto, S. L., et al. (2018). Synthesis of functionalized N-acetyl muramic acids to probe bacterial cell wall recycling and biosynthesis. J. Am. Chem. Soc. 140, 9458-9465. doi: 10.1021/jacs.8b03304

Dhar, S., Kumari, H., Balasubramanian, D., and Mathee, K. (2018). Cell-wall recycling and synthesis in Escherichia coli and Pseudomonas aeruginosa-their role in the development of resistance. J. Med. Microbiol. 67, 1-21. doi: 10.1099/jmm.0.000636

Diacovich, L., and Gorvel, J. P. (2010). Bacterial manipulation of innate immunity to promote infection. Nat. Rev. Microbiol. 8, 117-128. doi: 10.1038/nrmicro2295

Dietz, H., Pfeifle, D., and Wiedemann, B. (1997a). The signal molecule for beta-lactamase induction in enterobacter cloacae is the anhydromuramylpentapeptide. Antimicrob. Agents Chemother. 41, 2113-2120.

Dietz, H., Pfeifle, D., and Wiedemann, B. (1997b). The signal molecule for beta-lactamase induction in Enterobacter cloacae is the anhydromuramylpentapeptide. Antimicrob. Agents Chemother. 41, 2113-2120. doi: 10.1128/ Aac. 41.10 .2113 
Dijkstra, A. J., and Keck, W. (1996). Peptidoglycan as a barrier to transenvelope transport. J. Bacteriol. 178, 5555-5562. doi: 10.1128/jb.178.19.5555-5562.1996

Dik, D. A., Marous, D. R., Fisher, J. F., and Mobashery, S. (2017). Lytic transglycosylases: concinnity in concision of the bacterial cell wall. Crit. Rev. Biochem. Mol. Biol. 52, 503-542. doi: 10.1080/10409238.2017.1337705

Diziarski, R., and Gupta, D. (2010). Mammalian peptidoglycan recognition proteins (PGRPs) in innate immunity. Innate Immun. 16, 168-174. doi: $10.1177 / 1753425910366059$

Dominguez-Gil, T., Molina, R., Alcorlo, M., and Hermoso, J. A. (2016). Renew or die: the molecular mechanisms of peptidoglycan recycling and antibiotic resistance in Gram-negative pathogens. Drug Resist. Updat. 28, 91-104. doi: 10.1016/j.drup.2016.07.002

Donat, S., Streker, K., Schirmeister, T., Rakette, S., Stehle, T., Liebeke, M., et al. (2009). Transcriptome and functional analysis of the eukaryotic-type serine/threonine kinase PknB in Staphylococcus aureus. J. Bacteriol. 191, 4056-4069. doi: 10.1128/JB.00117-09

Doyle, R. J., Chaloupka, J., and Vinter, V. (1988). Turnover of cell walls in microorganisms. Microbiol. Rev. 52, 554-567.

Dramsi, S., Magnet, S., Davison, S., and Arthur, M. (2008). Covalent attachment of proteins to peptidoglycan. FEMS Microbiol. Rev. 32, 307-320. doi: 10.1111/j. 1574-6976.2008.00102.x

Dworkin, J. (2014). The medium is the message: interspecies and interkingdom signaling by peptidoglycan and related bacterial glycans. Annu. Rev. Microbiol. 68, 137-154. doi: 10.1146/annurev-micro-091213-112844

Dworkin, J. (2018). Detection of fungal and bacterial carbohydrates: do the similar structures of chitin and peptidoglycan play a role in immune dysfunction? PLoS Pathog. 14:e1007271. doi: 10.1371/journal.ppat.1007271

Dworkin, J., and Shah, I. M. (2010). Exit from dormancy in microbial organisms. Nat. Rev. Microbiol. 8, 890-896. doi: 10.1038/nrmicro2453

Dziarski, R. (2004). Peptidoglycan recognition proteins (PGRPs). Mol. Immunol. 40, 877-886. doi: 10.1016/j.molimm.2003.10.011

Dziarski, R., and Gupta, D. (2006). Mammalian PGRPs: novel antibacterial proteins. Cell. Microbiol. 8, 1059-1069. doi: 10.1111/j.1462-5822.2006.00726.x

Egan, A. J., Cleverley, R. M., Peters, K., Lewis, R. J., and Vollmer, W. (2017). Regulation of bacterial cell wall growth. FEBS J. 284, 851-867. doi: 10.1111/ febs. 13959

Fernandez, P., Saint-Joanis, B., Barilone, N., Jackson, M., Gicquel, B., Cole, S. T., et al. (2006). The Ser/Thr protein kinase $\mathrm{PknB}$ is essential for sustaining mycobacterial growth. J. Bacteriol. 188, 7778-7784. doi: 10.1128/JB.00963-06

Fillon, S., Soulis, K., Rajasekaran, S., Benedict-Hamilton, H., Radin, J. N., Orihuela, C. J., et al. (2006). Platelet-activating factor receptor and innate immunity: uptake of gram-positive bacterial cell wall into host cells and cell-specific pathophysiology. J. Immunol. 177, 6182-6191. doi: 10.4049/jimmunol.177.9.6182

Firczuk, M., and Bochtler, M. (2007). Folds and activities of peptidoglycan amidases. FEMS Microbiol. Rev. 31, 676-691. doi: 10.1111/j.1574-6976.2007.00084.x

Franchi, L., Warner, N., Viani, K., and Nunez, G. (2009). Function of Nod-like receptors in microbial recognition and host defense. Immunol. Rev. 227, 106-128. doi: 10.1111/j.1600-065X.2008.00734.x

Fritz, J. H., Ferrero, R. L., Philpott, D. J., and Girardin, S. E. (2006). Nod-like proteins in immunity, inflammation and disease. Nat. Immunol. 7, 1250-1257. doi: $10.1038 /$ ni1412

Garcia, D. L., and Dillard, J. P. (2008). Mutations in ampG or ampD affect peptidoglycan fragment release from Neisseria gonorrhoeae. J. Bacteriol. 190, 3799-3807. doi: 10.1128/JB.01194-07

Gerriets, V. A., Kishton, R. J., Nichols, A. G., Macintyre, A. N., Inoue, M., Ilkayeva, O., et al. (2015). Metabolic programming and PDHK1 control CD4+ T cell subsets and inflammation. J. Clin. Invest. 125, 194-207. doi: 10.1172/JCI76012

Girardin, S. E., Boneca, I. G., Carneiro, L. A., Antignac, A., Jehanno, M., Viala, J., et al. (2003a). Nod1 detects a unique muropeptide from gram-negative bacterial peptidoglycan. Science 300, 1584-1587. doi: 10.1126/science.1084677

Girardin, S. E., Boneca, I. G., Viala, J., Chamaillard, M., Labigne, A., Thomas, G., et al. (2003b). Nod2 is a general sensor of peptidoglycan through muramyl dipeptide (MDP) detection. J. Biol. Chem. 278, 8869-8872. doi: 10.1074/ jbc.C200651200

Girardin, S. E., Tournebize, R., Mavris, M., Page, A. L., Li, X., Stark, G. R., et al. (2001). CARD4/Nod1 mediates NF- $\mathrm{KB}$ and JNK activation by invasive Shigella flexneri. EMBO Rep. 2, 736-742. doi: 10.1093/embo-reports/kve155
Girardin, S. E., Travassos, L. H., Herve, M., Blanot, D., Boneca, I. G., Philpott, D. J., et al. (2003c). Peptidoglycan molecular requirements allowing detection by Nod1 and Nod2. J. Biol. Chem. 278, 41702-41708. doi: 10.1074/jbc. M307198200

Goldman, W. E., Klapper, D. G., and Baseman, J. B. (1982). Detection, isolation, and analysis of a released Bordetella pertussis product toxic to cultured tracheal cells. Infect. Immun. 36, 782-794.

Goodell, E. W. (1985). Recycling of murein by Escherichia coli. J. Bacteriol. 163, 305-310.

Goodell, E. W., and Schwarz, U. (1985). Release of cell-wall peptides into culturemedium by exponentially growing Escherichia coli. J. Bacteriol. 162, 391-397.

Goodson, M. S., Kojadinovic, M., Troll, J. V., Scheetz, T. E., Casavant, T. L., Soares, M. B., et al. (2005). Identifying components of the NF-kappaB pathway in the beneficial Euprymna scolopes-Vibrio fischeri light organ symbiosis. Appl. Environ. Microbiol. 71, 6934-6946. doi: 10.1128/AEM.71.11.6934-6946.2005

Gust, A. A. (2015). Peptidoglycan perception in plants. PLoS Pathog. 11:e1005275. doi: 10.1371/journal.ppat.1005275

Heffron, J. D., Orsburn, B., and Popham, D. L. (2009). Roles of germinationspecific lytic enzymes CwlJ and SleB in Bacillus anthracis. J. Bacteriol. 191, 2237-2247. doi: 10.1128/JB.01598-08

Heiss, L. N., Moser, S. A., Unanue, E. R., and Goldman, W. E. (1993). Interleukin-1 is linked to the respiratory epithelial cytopathology of pertussis. Infect. Immun. 61, 3123-3128.

Hergott, C. B., Roche, A. M., Tamashiro, E., Clarke, T. B., Bailey, A. G., Laughlin, A., et al. (2016). Peptidoglycan from the gut microbiota governs the lifespan of circulating phagocytes at homeostasis. Blood 127, 2460-2471. doi: 10.1182/blood-2015-10-675173

Hogan, D. A., and Kolter, R. (2002). Pseudomonas candida interactions: an ecological role for virulence factors. Science 296, 2229-2232. doi: 10.1126/ science. 1070784

Holtje, J. V. (1998). Growth of the stress-bearing and shape-maintaining murein sacculus of Escherichia coli. Microbiol. Mol. Biol. Rev. 62, 181-203.

Holtje, J. V., Kopp, U., Ursinus, A., and Wiedemann, B. (1994). The negative regulator of beta-lactamase induction Ampd is a n-acetyl-anhydromuramyl-l-alanine amidase FEMS Microbiol. Lett. 122, 159-164. doi: 10.1111/j.1574-6968.1994.tb07159.x

Holtje, J. V., Mirelman, D., Sharon, N., and Schwarz, U. (1975). Novel type of murein transglycosylase in Escherichia coli. J. Bacteriol. 124, 1067-1076.

Holtje, J. V., and Tuomanen, E. I. (1991). The murein hydrolases of Escherichia coli: properties, functions and impact on the course of infections in vivo. J. Gen. Microbiol. 137, 441-454. doi: 10.1099/00221287-137-3-441

Horcajo, P., de Pedro, M. A., and Cava, F. (2012). Peptidoglycan plasticity in bacteria: stress-induced peptidoglycan editing by noncanonical D-amino acids. Microb. Drug Resist. 18, 306-313. doi: 10.1089/mdr.2012.0009

Huang, M., and Hull, C. M. (2017). Sporulation: how to survive on planet Earth (and beyond). Curr. Genet. 63, 831-838. doi: 10.1007/s00294-017-0694-7

Huang, Y.-W., Wu, C.-J., Hu, R.-M., Lin, Y.-T., and Yang, T.-C. (2015). Interplay among membrane-bound lytic transglycosylase D1, the CreBC two-component regulatory system, the AmpNG-AmpDI-NagZ-AmpR regulatory circuit, and L1/L2 $\beta$-lactamase expression in Stenotrophomonas maltophilia. Antimicrob. Agents Chemother. 59, 6866-6872. doi: 10.1128/aac.05179-14

Ibrahim, H. R., Matsuzaki, T., and Aoki, T. (2001). Genetic evidence that antibacterial activity of lysozyme is independent of its catalytic function. Febs Lett. 506, 27-32. doi: 10.1016/S0014-5793(01)02872-1

Ikeda, S., Hanaki, H., Yanagisawa, C., Ikeda-Dantsuji, Y., Matsui, H., Iwatsuki, M., et al. (2010). Identification of the active component that induces vancomycin resistance in MRSA. J Antibiot 63, 533-538. doi: $10.1038 /$ ja. 2010.75

Inohara, N., and Nunez, G. (2003). NODs: intracellular proteins involved in inflammation and apoptosis. Nat. Rev. Immunol. 3, 371-382. doi: 10.1038/ nri1086

Jacobs, C. (1997). Pharmacia Biotech \& Science prize. 1997 grand prize winner. Life in the balance: cell walls and antibiotic resistance.. Science 278, 1731-1732. doi: $10.1126 /$ science.278.5344.1731b

Jacobs, C., Huang, L. J., Bartowsky, E., Normark, S., and Park, J. T. (1994). Bacterialcell wall recycling provides cytosolic muropeptides as effectors for beta-lactamase induction. Embo J. 13, 4684-4694. doi: 10.1002/j.1460-2075.1994.tb06792.x

Jacoby, G. A. (2009). AmpC beta-lactamases. Clin. Microbiol. Rev. 22, 161-182. doi: $10.1097 /$ AOG.0b013e3181b9d222 
Jaeger, T., and Mayer, C. (2008). N-acetylmuramic acid 6-phosphate lyases (MurNAc etherases): role in cell wall metabolism, distribution, structure, and mechanism. Cell. Mol. Life Sci. 65, 928-939. doi: 10.1007/s00018-007-7399-x

Jiang, H., Kong, R., and Xu, X. (2010). The N-acetylmuramic acid 6-phosphate etherase gene promotes growth and cell differentiation of cyanobacteria under light-limiting conditions. J. Bacteriol. 192, 2239-2245. doi: 10.1128/ JB.01661-09

Jo, E. K. (2008). Mycobacterial interaction with innate receptors: TLRs, C-type lectins, and NLRs. Curr. Opin. Infect. Dis. 21, 279-286. doi: 10.1097/ QCO.0b013e3282f88b5d

Johnson, J. W., Fisher, J. F., and Mobashery, S. (2013). Bacterial cell-wall recycling. Ann. N. Y. Acad. Sci. 1277, 54-75. doi: 10.1111/j.1749-6632.2012.06813.x

Kana, B. D., and Mizrahi, V. (2010). Resuscitation-promoting factors as lytic enzymes for bacterial growth and signaling. FEMS Immunol. Med. Microbiol. 58, 39-50. doi: 10.1111/j.1574-695X.2009.00606.x

Kanneganti, T. D., Lamkanfi, M., and Nunez, G. (2007). Intracellular NOD-like receptors in host defense and disease. Immunity 27, 549-559. doi: 10.1016/j. immuni.2007.10.002

Kaparakis, M., Turnbull, L., Carneiro, L., Firth, S., Coleman, H. A., Parkington, H. C., et al. (2010). Bacterial membrane vesicles deliver peptidoglycan to NOD1 in epithelial cells. Cell. Microbiol. 12, 372-385. doi: 10.1111/j.1462-5822.2009.01404.x

Kaparakis-Liaskos, M., and Ferrero, R. L. (2015). Immune modulation by bacterial outer membrane vesicles. Nat. Rev. Immunol. 15, 375-387. doi: $10.1038 /$ nri3837

Kashyap, D. R., Kuzma, M., Kowalczyk, D. A., Gupta, D., and Dziarski, R. (2017). Bactericidal peptidoglycan recognition protein induces oxidative stress in Escherichia coli through a block in respiratory chain and increase in central carbon catabolism. Mol. Microbiol. 105, 755-776. doi: 10.1111/ mmi. 13733

Kashyap, D. R., Rompca, A., Gaballa, A., Helmann, J. D., Chan, J., Chang, C. J., et al. (2014). Peptidoglycan recognition proteins kill bacteria by inducing oxidative, thiol, and metal stress. PLoS Pathog. 10:e1004280. doi: 10.1371/journal. ppat. 1004280

Keane, R., and Berleman, J. (2016). The predatory life cycle of Myxococcus xanthus. Microbiology 162, 1-11. doi: 10.1099/mic.0.000208

Keep, N. H., Ward, J. M., Cohen-Gonsaud, M., and Henderson, B. (2006). Wake up! Peptidoglycan lysis and bacterial non-growth states. Trends Microbiol. 14, 271-276. doi: 10.1016/j.tim.2006.04.003

Keestra-Gounder, A. M., and Tsolis, R. M. (2017). NOD1 and NOD2: beyond peptidoglycan sensing. Trends Immunol. 38, 758-767. doi: 10.1016/j. it.2017.07.004

Kluj, R. M., Ebner, P., Adamek, M., Ziemert, N., Mayer, C., and Borisova, M. (2018). Recovery of the peptidoglycan turnover product released by the autolysin Atl in Staphylococcus aureus involves the phosphotransferase system transporter MurP and the novel 6-phospho- $\mathrm{N}$-acetylmuramidase MupG. Front. Microbiol. 9, 1-14. doi: 10.3389/fmicb.2018.02725

Kohanski, M. A., Dwyer, D. J., and Collins, J. J. (2010). How antibiotics kill bacteria: from targets to networks. Nat. Rev. Microbiol. 8, 423-435. doi: $10.1038 /$ nrmicro2333

Konopka, J. B. (2012). N-acetylglucosamine (GlcNAc) functions in cell signaling. Scientifica 2012, 1-15. doi: 10.6064/2012/489208

Koraimann, G. (2003). Lytic transglycosylases in macromolecular transport systems of Gram-negative bacteria. Cell. Mol. Life Sci. 60, 2371-2388. doi: 10.1007/s00018-003-3056-1

Korgaonkar, A., Trivedi, U., Rumbaugh, K. P., and Whiteley, M. (2013). Community surveillance enhances Pseudomonas aeruginosa virulence during polymicrobial infection. Proc. Natl. Acad. Sci. USA 110, 1059-1064. doi: 10.1073/ pnas. 1214550110

Korgaonkar, A. K., and Whiteley, M. (2011). Pseudomonas aeruginosa enhances production of an antimicrobial in response to $\mathrm{N}$-acetylglucosamine and peptidoglycan. J. Bacteriol. 193, 909-917. doi: 10.1128/JB.01175-10

Koropatnick, T. A., Engle, J. T., Apicella, M. A., Stabb, E. V., Goldman, W. E., and McFall-Ngai, M. J. (2004). Microbial factor-mediated development in a host-bacterial mutualism. Science 306, 1186-1188. doi: 10.1126/ science. 1102218

Koropatnick, T. A., Kimbell, J. R., and McFall-Ngai, M. J. (2007). Responses of host hemocytes during the initiation of the squid-Vibrio symbiosis. Biol. Bull. 212, 29-39. doi: 10.2307/25066578
Korsak, D., Liebscher, S., and Vollmer, W. (2005). Susceptibility to antibiotics and beta-lactamase induction in murein hydrolase mutants of Escherichia coli. Antimicrob. Agents Chemother. 49, 1404-1409. doi: 10.1128/AAC.49.4.1404-1409.2005

Kraft, A. R., Prabhu, J., Ursinus, A., and Holtje, J. V. (1999). Interference with murein turnover has no effect on growth but reduces beta-lactamase induction in Escherichia coli. J. Bacteriol. 181, 7192-7198.

Krueger, J. M. (1985). Somnogenic activity of muramyl peptides. Trends Pharmacol. Sci. 6, 218-221. doi: 10.1016/0165-6147(85)90099-9

Krueger, J. M., and Opp, M. R. (2016). Sleep and microbes. Int. Rev. Neurobiol. 131, 207-225. doi: 10.1016/bs.irn.2016.07.003

Kulp, A., and Kuehn, M. J. (2010). Biological functions and biogenesis of secreted bacterial outer membrane vesicles. Annu. Rev. Microbiol. 64, 163-184. doi: 10.1146/annurev.micro.091208.073413

Kurata, S. (2014). Peptidoglycan recognition proteins in Drosophila immunity. Dev. Comp. Immunol. 42, 36-41. doi: 10.1016/j.dci.2013.06.006

Lamers, R. P., Nguyen, U. T., Nguyen, Y., Buensuceso, R. N., and Burrows, L. L. (2015). Loss of membrane-bound lytic transglycosylases increases outer membrane permeability and beta-lactam sensitivity in Pseudomonas aeruginosa. Microbiologyopen 4, 879-895. doi: 10.1002/mbo3.286

Layec, S., Decaris, B., and Leblond-Bourget, N. (2008). Diversity of Firmicutes peptidoglycan hydrolases and specificities of those involved in daughter cell separation. Res. Microbiol. 159, 507-515. doi: 10.1016/j.resmic.2008.06.008

Le Bourhis, L., Benko, S., and Girardin, S. E. (2007). Nod1 and Nod2 in innate immunity and human inflammatory disorders. Biochem. Soc. Trans. 35, 1479-1484. doi: 10.1042/BST0351479

Lee, M., Hesek, D., Shah, I. M., Oliver, A. G., Dworkin, J., and Mobashery, S. (2010). Synthetic peptidoglycan motifs for germination of bacterial spores. Chembiochem 11, 2525-2529. doi: 10.1002/cbic.201000626

Lee, M., Zhang, W., Hesek, D., Noll, B. C., Boggess, B., and Mobashery, S. (2009). Bacterial AmpD at the crossroads of peptidoglycan recycling and manifestation of antibiotic resistance. J. Am. Chem. Soc. 131, 8742-8743. doi: $10.1021 /$ ja9025566

Lehotzky, R. E., Partch, C. L., Mukherjee, S., Cash, H. L., Goldman, W. E., Gardner, K. H., et al. (2010). Molecular basis for peptidoglycan recognition by a bactericidal lectin. Proc. Natl. Acad. Sci. USA 107, 7722-7727. doi: 10.1073/pnas.0909449107

Lenz, J. D., Stohl, E. A., Robertson, R. M., Hackett, K. T., Fisher, K., Xiong, K., et al. (2016). Amidase activity of amic controls cell separation and stem peptide release and is enhanced by $\mathrm{NlpD}$ in Neisseria gonorrhoeae. J. Biol. Chem. 291, 10916-10933. doi: 10.1074/jbc.M116.715573

Li, L., Mendis, N., Trigui, H., Oliver, J. D., and Faucher, S. P. (2014). The importance of the viable but non-culturable state in human bacterial pathogens. Front. Microbiol. 5:258. doi: 10.3389/fmicb.2014.00258

Li, P., Ying, J., Yang, G., Li, A., Wang, J., Lu, J., et al. (2016). Structure-function analysis of the transmembrane protein AmpG from Pseudomonas aeruginosa. PLoS One 11:e0168060. doi: 10.1371/journal.pone.0168060

Litzinger, S., Duckworth, A., Nitzsche, K., Risinger, C., Wittmann, V., and Mayer, C. (2010). Muropeptide rescue in Bacillus subtilis involves sequential hydrolysis by beta-N-acetylglucosaminidase and $\mathrm{N}$-acetylmuramyl-L-alanine amidase. J. Bacteriol. 192, 3132-3143. doi: 10.1128/JB.01256-09

Liu, C., Gelius, E., Liu, G., Steiner, H., and Dziarski, R. (2000). Mammalian peptidoglycan recognition protein binds peptidoglycan with high affinity, is expressed in neutrophils, and inhibits bacterial growth. J. Biol. Chem. 275, 24490-24499. doi: 10.1074/jbc.M001239200

Lopez, R., Garcia, E., Garcia, P., and Garcia, J. L. (1997). The pneumococcal cell wall degrading enzymes: a modular design to create new lysins? Microb. Drug Resist. 3, 199-211. doi: 10.1089/mdr.1997.3.199

Lu, X., Wang, M., Qi, J., Wang, H., Li, X., Gupta, D., et al. (2006). Peptidoglycan recognition proteins are a new class of human bactericidal proteins. J. Biol. Chem. 281, 5895-5907. doi: 10.1074/jbc.M511631200

Maestro, B., Novakova, L., Hesek, D., Lee, M., Leyva, E., Mobashery, S., et al. (2011). Recognition of peptidoglycan and beta-lactam antibiotics by the extracellular domain of the Ser/Thr protein kinase StkP from Streptococcus pneumoniae. FEBS Lett. 585, 357-363. doi: 10.1016/j. febslet.2010.12.016

Mahapatra, S., Crick, D. C., McNeil, M. R., and Brennan, P. J. (2008). Unique structural features of the peptidoglycan of Mycobacterium leprae. J. Bacteriol. 190, 655-661. doi: 10.1128/JB.00982-07 
Maqbool, A., Herve, M., Mengin-Lecreulx, D., Wilkinson, A. J., and Thomas, G. H. (2012). MpaA is a murein-tripeptide-specific zinc carboxypeptidase that functions as part of a catabolic pathway for peptidoglycan-derived peptides in gamma-proteobacteria. Biochem. J. 448, 329-341. doi: 10.1042/ BJ20121164

Martinon, F., and Tschopp, J. (2005). NLRs join TLRs as innate sensors of pathogens. Trends Immunol. 26, 447-454. doi: 10.1016/j.it.2005.06.004

Mauck, J., Chan, L., and Glaser, L. (1971). Turnover of the cell wall of Gram-positive bacteria. J. Biol. Chem.

Mayer, S., Raulf, M. K., and Lepenies, B. (2017). C-type lectins: their network and roles in pathogen recognition and immunity. Histochem. Cell Biol. 147, 223-237. doi: 10.1007/s00418-016-1523-7

McDonald, C., Inohara, N., and Nunez, G. (2005). Peptidoglycan signaling in innate immunity and inflammatory disease. J. Biol. Chem. 280, 20177-20180. doi: 10.1074/jbc.R500001200

Mellroth, P., Karlsson, J., and Steiner, H. (2003). A scavenger function for a Drosophila peptidoglycan recognition protein. J. Biol. Chem. 278, 7059-7064. doi: 10.1074/jbc.M208900200

Melly, M. A., McGee, Z. A., and Rosenthal, R. S. (1984). Ability of monomeric peptidoglycan fragments from Neisseria gonorrhoeae to damage human fallopian-tube mucosa. J. Infect. Dis. 149, 378-386. doi: 10.1093/infdis/149.3.378

Mengin-Lecreulx, D., and Lemaitre, B. (2005). Structure and metabolism of peptidoglycan and molecular requirements allowing its detection by the Drosophila innate immune system. J. Endotoxin Res. 11, 105-111. doi: 10.1179/096805105X35233

Mengin-Lecreulx, D., van Heijenoort, J., and Park, J. T. (1996). Identification of the mpl gene encoding UDP-N-acetylmuramate: L-alanyl-gamma-Dglutamyl-meso-diaminopimelate ligase in Escherichia coli and its role in recycling of cell wall peptidoglycan. J. Bacteriol. 178, 5347-5352. doi: 10.1128/ jb.178.18.5347-5352.1996

Mesnage, S., Dellarole, M., Baxter, N. J., Rouget, J. B., Dimitrov, J. D., Wang, N., et al. (2014). Molecular basis for bacterial peptidoglycan recognition by LysM domains. Nat. Commun. 5, 4269. doi: 10.1038/ncomms5269

Meylan, E., Tschopp, J., and Karin, M. (2006). Intracellular pattern recognition receptors in the host response. Nature 442, 39-44. doi: 10.1038/nature04946

Mir, M., Asong, J., Li, X., Cardot, J., Boons, G. J., and Husson, R. N. (2011). The extracytoplasmic domain of the Mycobacterium tuberculosis Ser/Thr kinase PknB binds specific muropeptides and is required for PknB localization. PLoS Pathog. 7:e1002182. doi: 10.1371/journal.ppat.1002182

Mogensen, T. H. (2009). Pathogen recognition and inflammatory signaling in innate immune defenses. Clin. Microbiol. Rev. 22, 240-273. doi: 10.1186/1471-2180-9-281

Morlot, C., Uehara, T., Marquis, K. A., Bernhardt, T. G., and Rudner, D. Z. (2010). A highly coordinated cell wall degradation machine governs spore morphogenesis in Bacillus subtilis. Genes Dev. 24, 411-422. doi: 10.1101/gad.1878110

Moya, B., Dotsch, A., Juan, C., Blazquez, J., Zamorano, L., Haussler, S., et al. (2009). Beta-lactam resistance response triggered by inactivation of a nonessential penicillin-binding protein. PLoS Pathog. 5:e1000353. doi: 10.1371/ journal.ppat.1000353

Moynihan, P. J., Sychantha, D., and Clarke, A. J. (2014). Chemical biology of peptidoglycan acetylation and deacetylation. Bioorg. Chem. 54, 44-50. doi: 10.1016/j.bioorg.2014.03.010

Mukamolova, G. V., Murzin, A. G., Salina, E. G., Demina, G. R., Kell, D. B., Kaprelyants, A. S., et al. (2006). Muralytic activity of Micrococcus luteus $\mathrm{Rpf}$ and its relationship to physiological activity in promoting bacterial growth and resuscitation. Mol. Microbiol. 59, 84-98. doi: 10.1111/j. 1365-2958.2005.04930.x

Mukamolova, G. V., Turapov, O. A., Kazarian, K., Telkov, M., Kaprelyants, A. S., Kell, D. B., et al. (2002). The rpf gene of Micrococcus luteus encodes an essential secreted growth factor. Mol. Microbiol. 46, 611-621. doi: 10.1046/j. 1365-2958.2002.03183.x

Muller, A., Klockner, A., and Schneider, T. (2017). Targeting a cell wall biosynthesis hot spot. Nat. Prod. Rep. 34, 909-932. doi: 10.1039/c7np00012j

Nadesalingam, J., Dodds, A. W., Reid, K. B. M., and Palaniyar, N. (2005). Mannose-binding lectin recognizes peptidoglycan via the $\mathrm{N}$-acetyl glucosamine moiety, and inhibits ligand-induced proinflammatory effect and promotes chemokine production by macrophages. J. Immunol. 175, 1785-1794. doi: 10.4049/jimmunol.175.3.1785
Nanninga, N. (1998). Morphogenesis of Escherichia coli. Microbiol. Mol. Biol. Rev. 62, 110-129.

Naseem, S., Parrino, S. M., Buenten, D. M., and Konopka, J. B. (2012). Novel roles for GlcNAc in cell signaling. Commun. Integr. Biol. 5, 156-159. doi: 10.4161/cib.19034

Neuhaus, F. C., and Baddiley, J. (2003). A continuum of anionic charge: structures and functions of d-alanyl-teichoic acids in gram-positive bacteria. Microbiol. Mol. Biol. Rev. 67, 686-723. doi: 10.1128/mmbr.67.4.686-723.2003

Nigro, G., Fazio, L. L., Martino, M. C., Rossi, G., Tattoli, I., Liparoti, V., et al. (2008). Muramylpeptide shedding modulates cell sensing of Shigella flexneri. Cell. Microbiol. 10, 682-695. doi: 10.1111/j.1462-5822.2007.01075.x

Nyholm, S. V. (2009). Peptidoglycan monomer release and Vibrio fischeri. J. Bacteriol. 191, 1997-1999. doi: 10.1128/JB.01801-08

Nyholm, S. V., Stabb, E. V., Ruby, E. G., and McFall-Ngai, M. J. (2000). Establishment of an animal-bacterial association: recruiting symbiotic vibrios from the environment. PNAS 97, 10231-10235.

Ohnuma, T., Onaga, S., Murata, K., Taira, T., and Katoh, E. (2008). LysM domains from Pteris ryukyuensis chitinase-A: a stability study and characterization of the chitin-binding site. J. Biol. Chem. 283, 5178-5187. doi: 10.1074/jbc.M707156200

Oliver, J. D. (2005). The viable but nonculturable state in bacteria. J. Microbiol. 43, 93-100. doi: 10.1016/j.jns.2004.11.042

Park, J. T., and Uehara, T. (2008). How bacteria consume their own exoskeletons (turnover and recycling of cell wall peptidoglycan). Microbiol. Mol. Biol. Rev. 72, 211-227. doi: 10.1128/MMBR.00027-07

Pashenkov, M. V., Dagil, Y. A., and Pinegin, B. V. (2018). NOD1 and NOD2: molecular targets in prevention and treatment of infectious diseases. doi: 10.1016/j.intimp.2017.11.036

Pensinger, D. A., Schaenzer, A. J., and Sauer, J. D. (2018). Do shoot the messenger: PASTA kinases as virulence determinants and antibiotic targets. Trends Microbiol. 26, 56-69. doi: 10.1016/j.tim.2017.06.010

Perley-Robertson, G. E., Yadav, A. K., Winogrodzki, J. L., Stubbs, K. A., Mark, B. L., and Vocadlo, D. J. (2016). A fluorescent transport assay enables studying AmpG permeases involved in peptidoglycan recycling and antibiotic resistance. ACS Chem. Biol. 11, 2626-2635. doi: 10.1021/ acschembio.6b00552

Peterson, S. B., Dunn, A. K., Klimowicz, A. K., and Handelsman, J. (2006). Peptidoglycan from Bacillus cereus mediates commensalism with rhizosphere bacteria from the Cytophaga-Flavobacterium group. Appl. Environ. Microbiol. 72, 5421-5427. doi: 10.1128/AEM.02928-05

Philpott, D. J., Sorbara, M. T., Robertson, S. J., Croitoru, K., and Girardin, S. E. (2014). NOD proteins: regulators of inflammation in health and disease. Nat. Rev. Immunol. 14, 9-23. doi: 10.1038/nri3565

Philpott, D. J., Yamaoka, S., Israel, A., and Sansonetti, P. J. (2000). Invasive Shigella flexneri activates NF-B through a lipopolysaccharide-dependent innate intracellular response and leads to IL-8 expression in epithelial cells. J. Immunol. 165, 903-914. doi: 10.4049/jimmunol.165.2.903

Plato, A., Willment, J. A., and Brown, G. D. (2013). C-type lectin-like receptors of the dectin-1 cluster: ligands and signaling pathways. Int. Rev. Immunol. 32, 134-156. doi: 10.3109/08830185.2013.777065

Popham, D. L., and Bernhards, C. B. (2015). Spore peptidoglycan. Microbiol. Spectr. 3. doi: 10.1128/microbiolspec.TBS-0005-2012

Ragland, S. A., and Criss, A. K. (2017). From bacterial killing to immune modulation: recent insights into the functions of lysozyme. PLoS Pathog. 13:e1006512. doi: 10.1371/journal.ppat.1006512

Reith, J., and Mayer, C. (2011). Peptidoglycan turnover and recycling in Grampositive bacteria. Appl. Microbiol. Biotechnol. 92, 1-11. doi: 10.1007/ s00253-011-3486-x

Rice, K. C., and Bayles, K. W. (2008). Molecular control of bacterial death and lysis. Microbiol. Mol. Biol. Rev. 72, 85-109. doi: 10.1128/MMBR.00030-07

Rigali, S., Nothaft, H., Noens, E. E., Schlicht, M., Colson, S., Muller, M., et al. (2006). The sugar phosphotransferase system of Streptomyces coelicolor is regulated by the GntR-family regulator DasR and links N-acetylglucosamine metabolism to the control of development. Mol. Microbiol. 61, 1237-1251. doi: 10.1111/j.1365-2958.2006.05319.x

Rolain, T., Bernard, E., Courtin, P., Bron, P. A., Kleerebezem, M., ChapotChartier, M. P., et al. (2012). Identification of key peptidoglycan hydrolases for morphogenesis, autolysis, and peptidoglycan composition of 
Lactobacillus plantarum WCFS1. Microb. Cell Factories 11, 137. doi: 10.1186/1475-2859-11-137

Rosenthal, R. S., Nogami, W., Cookson, B. T., Goldman, W. E., and Folkening, W. J. (1987). Major fragment of soluble peptidoglycan released from growing bordetella-pertussis is tracheal cytotoxin. Infect. Immun. 55, 2117-2120.

Royet, J., and Dziarski, R. (2007). Peptidoglycan recognition proteins: pleiotropic sensors and effectors of antimicrobial defences. Nat. Rev. Microbiol. 5, 264-277. doi: 10.1038/nrmicro1620

Royet, J., Gupta, D., and Dziarski, R. (2011). Peptidoglycan recognition proteins: modulators of the microbiome and inflammation. Nat. Rev. Immunol. 11, 837-851. doi: 10.1038/nri3089

Ruscitto, A., Honma, K., Veeramachineni, V. M., Nishikawa, K., Stafford, G. P., and Sharma, A. (2017). Regulation and molecular basis of environmental muropeptide uptake and utilization in fastidious oral anaerobe Tannerella forsythia. Front. Microbiol. 8:648. doi: 10.3389/fmicb.2017.00648

Santin, Y. G., and Cascales, E. (2017). Domestication of a housekeeping transglycosylase for assembly of a Type VI secretion system. EMBO Rep. 18, 138-149. doi: 10.15252/embr.201643206

Schaub, R. E., Chan, Y. A., Lee, M., Hesek, D., Mobashery, S., and Dillard, J. P. (2016). Lytic transglycosylases LtgA and LtgD perform distinct roles in remodeling, recycling and releasing peptidoglycan in Neisseria gonorrhoeae. Mol. Microbiol. 102, 865-881. doi: 10.1111/mmi.13496

Scheurwater, E. M., and Burrows, L. L. (2011). Maintaining network security: how macromolecular structures cross the peptidoglycan layer. FEMS Microbiol. Lett. 318, 1-9. doi: 10.1111/j.1574-6968.2011.02228.x

Scheurwater, E., Reid, C. W., and Clarke, A. J. (2008). Lytic transglycosylases: bacterial space-making autolysins. Int. J. Biochem. Cell Biol. 40, 586-591. doi: 10.1016/j.biocel.2007.03.018

Schleifer, K. H., and Kandler, O. (1972). Peptidoglycan types of bacterial cellwalls and their taxonomic implications. Bacteriol. Rev. 36, 407-477.

Schmidt, D. M., Hubbard, B. K., and Gerlt, J. A. (2001). Evolution of enzymatic activities in the enolase superfamily: functional assignment of unknown proteins in Bacillus subtilis and Escherichia coli as L-Ala-D/L-Glu epimerases. Biochemistry 40, 15707-15715. doi: 10.1021/bi011640x

Schroeder, U., Henrich, B., Fink, J., and Plapp, R. (1994). Peptidase D of Escherichia coli K-12, a metallopeptidase of low substrate specificity. FEMS Microbiol. Lett. 123, 153-159.

Sebaihia, M., Wren, B. W., Mullany, P., Fairweather, N. F., Minton, N., Stabler, R., et al. (2006). The multidrug-resistant human pathogen Clostridium difficile has a highly mobile, mosaic genome. Nat. Genet. 38, 779-786. doi: 10.1038/ ng1830

Shah, I. M., Laaberki, M. H., Popham, D. L., and Dworkin, J. (2008). A eukaryotic-like Ser/Thr kinase signals bacteria to exit dormancy in response to peptidoglycan fragments. Cell 135, 486-496. doi: 10.1016/j.cell.2008.08.039

Sharma, P., Dube, D., Singh, A., Mishra, B., Singh, N., Sinha, M., et al. (2011). Structural basis of recognition of pathogen-associated molecular patterns and inhibition of proinflammatory cytokines by camel peptidoglycan recognition protein. J. Biol. Chem. 286, 16208-16217. doi: 10.1074/jbc.M111.228163

Sharma, A. K., Kumar, S., K, H., Dhakan, D. B., and Sharma, V. K. (2016). Prediction of peptidoglycan hydrolases- a new class of antibacterial proteins. BMC Genomics 17, 411. doi: 10.1186/s12864-016-2753-8

Shi, L., Takahashi, K., Dundee, J., Shahroor-Karni, S., Thiel, S., Jensenius, J. C., et al. (2004). Mannose-binding lectin-deficient mice are susceptible to infection with Staphylococcus aureus. J. Exp. Med. 199, 1379-1390. doi: $10.1084 /$ jem.20032207

Shimada, T., Park, B. G., Wolf, A. J., Brikos, C., Goodridge, H. S., Becker, C. A., et al. (2010). Staphylococcus aureus evades lysozyme-based peptidoglycan digestion that links phagocytosis, inflammasome activation, and IL-1beta secretion. Cell Host Microbe 7, 38-49. doi: 10.1016/j.chom.2009.12.008

Shimada, T., Yamazaki, K., and Ishihama, A. (2013). Novel regulator PgrR for switch control of peptidoglycan recycling in Escherichia coli. Genes Cells 18, 123-134. doi: $10.1111 /$ gtc. 12026

Shimkets, L. J., and Kaiser, D. (1982). Induction of coordinated movement of Myxococcus xanthus cells. J. Bacteriol. 152, 451-461.

Shockman, G. D., Daneo-Moore, L., Kariyama, R., and Massidda, O. (1996). Bacterial walls, peptidoglycan hydrolases, autolysins, and autolysis. Microb. Drug Resist. 2, 95-98. doi: 10.1089/mdr.1996.2.95
Singh, S. K., SaiSree, L., Amrutha, R. N., and Reddy, M. (2012). Three redundant murein endopeptidases catalyse an essential cleavage step in peptidoglycan synthesis of Escherichia coli K12. Mol. Microbiol. 86, 1036-1051. doi: 10.1111/ mmi. 12058

Sinha, R. K., and Rosenthal, R. S. (1980). Release of soluble peptidoglycan from growing conococci: demonstration of anhydro-muramyl-containing fragments. Infect. Immun. 29, 914-925.

Sinha, R. K., and Rosenthal, R. S. (1981). Effect of penicillin G on release of peptidoglycan fragments by Neisseria gonorrhoeae: characterization of extracellular products. Antimicrob. Agents Chemother. 20, 98-103. doi: 10.1128/ AAC.20.1.98

Smith, T. J., Blackman, S. A., and Foster, S. J. (2000). Autolysins of Bacillus subtilis: multiple enzymes with multiple functions. Microbiology 146, 249-262. doi: 10.1099/00221287-146-2-249

Sorbara, M. T., and Philpott, D. J. (2011). Peptidoglycan: a critical activator of the mammalian immune system during infection and homeostasis. Immunol. Rev. 243, 40-60. doi: 10.1111/j.1600-065X.2011.01047.x

Squeglia, F., Marchetti, R., Ruggiero, A., Lanzetta, R., Marasco, D., Dworkin, J., et al. (2011). Chemical basis of peptidoglycan discrimination by PrkC, a key kinase involved in bacterial resuscitation from dormancy. J. Am. Chem. Soc. 133, 20676-20679. doi: 10.1021/ja208080r

Steen, A., Buist, G., Horsburgh, G. J., Venema, G., Kuipers, O. P., Foster, S. J., et al. (2005). AcmA of Lactococcus lactis is an $\mathrm{N}$-acetylglucosaminidase with an optimal number of LysM domains for proper functioning. FEBS J. 272, 2854-2868. doi: 10.1111/j.1742-4658.2005.04706.x

Stohl, E. A., Dale, E. M., Criss, A. K., and Seifert, H. S. (2013). Neisseria gonorrhoeae metalloprotease NGO1686 is required for full piliation, and piliation is required for resistance to $\mathrm{H}_{2} \mathrm{O}_{2}$ - and neutrophil-mediated killing. MBio 4, 1-9. doi: 10.1128/mBio.00399-13

Strober, W., Murray, P. J., Kitani, A., and Watanabe, T. (2006). Signalling pathways and molecular interactions of NOD1 and NOD2. Nat. Rev. Immunol. 6, 9-20. doi: 10.1038/nri1747

Sukhithasri, V., Nisha, N., Biswas, L., Anil Kumar, V., and Biswas, R. (2013). Innate immune recognition of microbial cell wall components and microbial strategies to evade such recognitions. Microbiol. Res. 168, 396-406. doi: 10.1016/j.micres.2013.02.005

Swaan, P. W., Bensman, T., Bahadduri, P. M., Hall, M. W., Sarkar, A., Bao, S., et al. (2008). Bacterial peptide recognition and immune activation facilitated by human peptide transporter PEPT2. Am. J. Respir. Cell Mol. Biol. 39, 536-542. doi: 10.1165/rcmb.2008-0059OC

Tayler, A. E., Ayala, J. A., Niumsup, P., Westphal, K., Baker, J. A., and Zhang, L., et al. (2010). Induction of beta-lactamase production in Aeromonas hydrophila is responsive to beta-lactam-mediated changes in peptidoglycan composition. Microbiology 156, 2327-2335. doi: 10.1099/ mic. $0.035220-0$

Templin, M. F., Ursinus, A., and Holtje, J. V. (1999). A defect in cell wall recycling triggers autolysis during the stationary growth phase of Escherichia coli. EMBO J. 18, 4108-4117. doi: 10.1093/emboj/18.15.4108

Thunnissen, A. M., Rozeboom, H. J., Kalk, K. H., and Dijkstra, B. W. (1995), Structure of the 70-kDa soluble lytic transglycosylase complexed with bulgecin A. Implications for the enzymatic mechanism. Biochemistry 34, 12729-12737. doi: $10.1021 /$ bi00039a032

Troll, J. V., Bent, E. H., Pacquette, N., Wier, A. M., Goldman, W. E., Silverman, N., et al. (2010). Taming the symbiont for coexistence: a host PGRP neutralizes a bacterial symbiont toxin. Environ. Microbiol. 12, 2190-2203. doi: 10.1111/j.1462-2920.2009.02121.x

Tsui, H. C., Zheng, J. J., Magallon, A. N., Ryan, J. D., Yunck, R., Rued, B. E., et al. (2016). Suppression of a deletion mutation in the gene encoding essential PBP2b reveals a new lytic transglycosylase involved in peripheral peptidoglycan synthesis in Streptococcus pneumoniae D39. Mol. Microbiol. 100, 1039-1065. doi: 10.1111/mmi.13366

Turner, R. D., Vollmer, W., and Foster, S. J. (2014). Different walls for rods and balls: the diversity of peptidoglycan. Mol. Microbiol. 91, 862-874. doi: $10.1111 / \mathrm{mmi} .12513$

Tydell, C. C., Yuan, J., Tran, P., and Selsted, M. E. (2006). Bovine peptidoglycan recognition protein-S: antimicrobial activity, localization, secretion, and binding properties. J. Immunol. 176, 1154-1162. doi: 10.4049/ jimmunol.176.2.1154 
Typas, A., Banzhaf, M., Gross, C. A., and Vollmer, W. (2011). From the regulation of peptidoglycan synthesis to bacterial growth and morphology. Nat. Rev. Microbiol. 10, 123-136. doi: 10.1038/nrmicro2677

Uehara, T., and Bernhardt, T. G. (2011). More than just lysins: peptidoglycan hydrolases tailor the cell wall. Curr. Opin. Microbiol. 14, 698-703. doi: 10.1016/j.mib.2011.10.003

Uehara, T., and Park, J. T. (2002). Role of the murein precursor UDP-Nacetylmuramyl-L-Ala- -D-Glu- meso-diaminopimelic acid-D-Ala-D-Ala in repression of -lactamase induction in cell division mutants. J. Bacteriol. 184, 4233-4239. doi: 10.1128/jb.184.15.4233-4239.2002

Uehara, T., and Park, J. T. (2003). Identification of MpaA, an amidase in Escherichia coli that hydrolyzes the gamma-D-glutamyl-meso-diaminopimelate bond in murein peptides. J. Bacteriol. 185, 679-682. doi: 10.1128/JB.185.2.679-682.2003

Uehara, T., and Park, J. T. (2008). Peptidoglycan recycling. EcoSal Plus 3, 1-8. doi: 10.1128/ecosalplus.4.7.1.5

Uehara, T., Parzych, K. R., Dinh, T., and Bernhardt, T. G. (2010). Daughter cell separation is controlled by cytokinetic ring-activated cell wall hydrolysis. EMBO J. 29, 1412-1422. doi: 10.1038/emboj.2010.36

Uehara, T., Suefuji, K., Jaeger, T., Mayer, C., and Park, J. T. (2006). MurQ etherase is required by Escherichia coli in order to metabolize anhydro-Nacetylmuramic acid obtained either from the environment or from its own cell wall. J. Bacteriol. 188, 1660-1662. doi: 10.1128/JB.188.4.1660-1662.2006

Uehara, T., Suefuji, K., Valbuena, N., Meehan, B., Donegan, M., and Park, J. T. (2005). Recycling of the anhydro-N-acetylmuramic acid derived from cell wall murein involves a two-step conversion to $\mathrm{N}$-acetylglucosamine-phosphate. J. Bacteriol. 187, 3643-3649. doi: 10.1128/JB.187.11.3643-3649.2005

van Ampting, M. T., Loonen, L. M., Schonewille, A. J., Konings, I., Vink, C., Iovanna, J., et al. (2012). Intestinally secreted C-type lectin Reg3b attenuates salmonellosis but not listeriosis in mice. Infect. Immun. 80, 1115-1120. doi: 10.1128/IAI.06165-11

van Heijenoort, J. (2011). Peptidoglycan hydrolases of Escherichia coli. Microbiol. Mol. Biol. Rev. 75, 636-663. doi: 10.1128/MMBR.00022-11

Vavricka, S. R., Musch, M. W., Chang, J. E., Nakagawa, Y., Phanvijhitsiri, K., Waypa, T. S., et al. (2004). hPepT1 transports muramyl dipeptide, activating NF- $\mathrm{KB}$ and stimulating IL-8 secretion in human colonic Caco2/bbe cells. Gastroenterology 127, 1401-1409. doi: 10.1053/j.gastro.2004.07.024

Vollmer, W., and Bertsche, U. (2008). Murein (peptidoglycan) structure, architecture and biosynthesis in Escherichia coli. Biochim. Biophys. Acta 1778, 1714-1734. doi: 10.1016/j.bbamem.2007.06.007

Vollmer, W., Blanot, D., and de Pedro, M. A. (2008a). Peptidoglycan structure and architecture. FEMS Microbiol. Rev. 32, 149-167. doi: 10.1111/j.1574-6976.2007.00094.x

Vollmer, W., Joris, B., Charlier, P., and Foster, S. (2008b). Bacterial peptidoglycan (murein) hydrolases. FEMS Microbiol. Rev. 32, 259-286. doi: 10.1111/j.1574-6976.2007.00099.x

Votsch, W., and Templin, M. F. (2000). Characterization of a beta -Nacetylglucosaminidase of Escherichia coli and elucidation of its role in muropeptide recycling and beta -lactamase induction. J. Biol. Chem. 275, 39032-39038. doi: 10.1074/jbc.M004797200

Waldemar, V. (2012). Bacterial growth does require peptidoglycan hydrolases. Mol. Microbiol. 86, 1031-1035. doi: 10.1111/mmi.12059

White, R. J., and Pasternak, C. A. (1967). The purification and properties of $\mathrm{N}$-acetylglucosamine 6-phosphate deacetylase from Escherichia coli. Biochem. J. 105, 121-125. doi: 10.1042/bj1050121

Wiedemann, B., Dietz, H., and Pfeifle, D. (1998). Induction of beta-lactamase in Enterobacter cloacae. Clin. Infect. Dis. 27(Suppl. 1), S42-S47.

Wolf, A. J., Reyes, C. N., Liang, W., Becker, C., Shimada, K., Wheeler, M. L., et al. (2016). Hexokinase is an innate immune receptor for the detection of bacterial peptidoglycan. Cell 166, 624-636. doi: 10.1016/j.cell.2016.05.076
Wolf, A. J., and Underhill, D. M. (2018). Peptidoglycan recognition by the innate immune system. Nat. Rev. Immunol. 18, 243-254. doi: 10.1038/ nri.2017.136

Wong, J. E., Alsarraf, H. M., Kaspersen, J. D., Pedersen, J. S., Stougaard, J., Thirup, S., et al. (2014). Cooperative binding of LysM domains determines the carbohydrate affinity of a bacterial endopeptidase protein. FEBS J. 281, 1196-1208. doi: 10.1111/febs. 12698

Wong, W., Young, F. E., and Chatterjee, A. N. (1974). Regulation of bacterial cell walls: turnover of cell wall in Staphylococcus aureus. J. Bacteriol. 120, 837-843.

Wood, T. K., Knabel, S. J., and Kwan, B. W. (2013). Bacterial persister cell formation and dormancy. Appl. Environ. Microbiol. 79, 7116-7121. doi: 10.1128/AEM.02636-13

Woodhams, K. L., Chan, J. M., Lenz, J. D., Hackett, K. T., and Dillard, J. P. (2013). Peptidoglycan fragment release from Neisseria meningitidis. Infect. Immun. 81, 3490-3498. doi: 10.1128/IAI.00279-13

Wyckoff, T. J., Taylor, J. A., and Salama, N. R. (2012). Beyond growth: novel functions for bacterial cell wall hydrolases. Trends Microbiol. 20, 540-547. doi: $10.1016 /$ j.tim.2012.08.003

Wydau-Dematteis, S., El Meouche, I., Courtin, P., Hamiot, A., Lai-Kuen, R., Saubaméa, B., et al. (2018). Cwp19 is a novel lytic transglycosylase involved in stationary-phase autolysis resulting in toxin release in clostridium difficile. mBio 9, e00648-e00618. doi: 10.1128/mBio.00648-18

Xu, X. L., Lee, R. T., Fang, H. M., Wang, Y. M., Li, R., Zou, H., et al. (2008). Bacterial peptidoglycan triggers Candida albicans hyphal growth by directly activating the adenylyl cyclase Cyrlp. Cell Host Microbe 4, 28-39. doi: 10.1016/j.chom.2008.05.014

Yadav, A., Espaillat, A., and Cava, F. (2018). Bacterial strategies to preserve cell wall integrity against environmental threats. Front. Microbiol. 9:2064. doi: 10.3389/FMICB.2018.02064

Yeats, C., Finn, R. D., and Bateman, A. (2002). The PASTA domain: a betalactam-binding domain. Trends Biochem. Sci. 27, 438. doi: 10.1016/ S0968-0004(02)02164-3

Yin, J., Mao, Y., Ju, L., Jin, M., Sun, Y., Jin, S., et al. (2014). Distinct roles of major peptidoglycan recycling enzymes in beta-Lactamase production in Shewanella oneidensis. Antimicrob. Agents Chemother. 58, 6536-6543. doi: 10.1128/AAC.03238-14

Zeng, X., and Lin, J. (2013). Beta-lactamase induction and cell wall metabolism in Gram-negative bacteria. Front Microbiol. 4:128. doi: 10.3389/fmicb.2013.00128

Zhang, Y., Bao, Q., Gagnon, L. A., Huletsky, A., Oliver, A., Jin, S., et al. (2010). ampG gene of Pseudomonas aeruginosa and its role in beta-lactamase expression. Antimicrob. Agents Chemother. 54, 4772-4779. doi: 10.1128/AAC.00009-10

Zhang, X. C., Cannon, S. B., and Stacey, G. (2009). Evolutionary genomics of LysM genes in land plants. BMC Evol. Biol. 9, 183. doi: 10.1186/1471-2148-9-183 Zipfel, C. (2014). Plant pattern-recognition receptors. Trends Immunol. 35, 345-351. doi: 10.1016/j.it.2014.05.004

Conflict of Interest Statement: The authors declare that the research was conducted in the absence of any commercial or financial relationships that could be construed as a potential conflict of interest.

Copyright (C) 2019 Irazoki, Hernandez and Cava. This is an open-access article distributed under the terms of the Creative Commons Attribution License (CC $B Y)$. The use, distribution or reproduction in other forums is permitted, provided the original author(s) and the copyright owner(s) are credited and that the original publication in this journal is cited, in accordance with accepted academic practice. No use, distribution or reproduction is permitted which does not comply with these terms. 